\title{
A climatology of surface ozone in the extra tropics: cluster analysis of observations and model results
}

\author{
O. A. Tarasova ${ }^{1,2}$, C. A. M. Brenninkmeijer ${ }^{1}$, P. Jöckel ${ }^{1}$, A. M. Zvyagintsev ${ }^{3}$, and G. I. Kuznetsov ${ }^{2}$ \\ ${ }^{1}$ Max Planck Institute for Chemistry, Mainz, Germany \\ ${ }^{2}$ Lomonosov Moscow State University, Faculty of Physics, Moscow, Russia \\ ${ }^{3}$ Central Aerological Observatory, Dolgoprudny, Russia
}

Received: 6 July 2007 - Published in Atmos. Chem. Phys. Discuss.: 23 August 2007

Revised: 14 November 2007 - Accepted: 20 November 2007 - Published: 12 December 2007

\begin{abstract}
Important aspects of the seasonal variations of surface ozone are discussed. The underlying analysis is based on the long-term (1990-2004) ozone records of the Co-operative Programme for Monitoring and Evaluation of the Long-range Transmission of Air Pollutants in Europe (EMEP) and the World Data Centre of Greenhouse Gases, which provide data mostly for the Northern Hemisphere. Seasonal variations are pronounced at most of the 114 locations at all times of the day. A seasonal-diurnal variations classification using hierarchical agglomeration clustering reveals 6 distinct clusters: clean background, rural, semipolluted non-elevated, semi-polluted semi-elevated, elevated and polar/remote marine. For the "clean background" cluster the seasonal maximum is observed in March-April, both for night and day. For those sites with a double maximum or a wide spring-summer maximum, the spring maximum appears both for day and night, while the summer maximum is more pronounced for daytime and hence can be attributed to photochemical processes. The spring maximum is more likely caused by dynamical/transport processes than by photochemistry as it is observed in spring for all times of the day. We compare the identified clusters with corresponding data from the 3-D atmospheric chemistry general circulation model ECHAM5/MESSy1 covering the period of 1998-2005. For the model output as for the measurements 6 clusters are considered. The simulation shows at most of the sites a spring seasonal maximum or a broad spring-summer maximum (with higher summer mixing ratios). For southern hemispheric and polar remote locations the seasonal maximum in the simulation is shifted to spring, while the absolute mixing ratios are in good agreement with the measurements. The seasonality in the model cluster covering background locations is characterized by a pronounced spring (AprilMay) maximum. For the model clusters which cover rural
\end{abstract}

Correspondence to: O. A. Tarasova

(tarasova@mpch-mainz.mpg.de) and semi-polluted sites the role of the photochemical production/destruction seems to be overestimated. Taking into consideration the differences in the data sampling procedure, the comparison demonstrates the ability of the model to reproduce the main regimes of surface ozone variations quite well.

\section{Introduction}

Ozone is a key species of tropospheric chemistry, polluted or pristine (Crutzen, 1973; Fabian and Pruchniewz, 1977), and it is a greenhouse gas (IPCC, 2006). Surface ozone is of special concern as an air pollutant. Particularly, despite the measures taken to ameliorate surface ozone increase by reducing precursor emissions (Ordóñez et al., 2005; Vingarzan, 2004; Oltmans et al., 2006), its level appears to be increasing. Jonson et al. (2006) suggested that reductions in regional ozone production were annulled by increasing levels of background ozone, thus leading to the upward trend observed at Mace Head in Ireland. A possible explanation of the positive trend at the elevated European sites has been proposed by Ordóñez et al. (2007), who suggested that an increased contribution of stratospheric ozone was the main reason for the tropospheric ozone increase in the $90 \mathrm{~s}$. Even over parts of the Atlantic Ocean ozone has been increasing (Lelieveld et al., 2004), attributed to increases in anthropogenic NOx emissions in Africa. At the same time at certain locations surface ozone trends can be negative (Tarasova et al., 2003; Vingarzan, 2004). Altogether a deeper understanding of ozone, of its spatial variability, its temporal variations, trends and ultimately its budget is still required. The diversity of the processes that control and affect tropospheric ozone combined with its variable rather short lifetime constitutes a most complex system. Careful analyses of the many observations of this interesting gas contribute to our understanding, as do

Published by Copernicus Publications on behalf of the European Geosciences Union. 
model simulations. In this paper we will combine both approaches for a better understanding of extra-tropical ozone.

Surface ozone over the continents has a pronounced seasonal cycle (e.g. Tropospheric Ozone Research, TOR-2 final report; Zvyagintsev, 2004). The shape of this cycle depends primarily on the latitude (insolation), on the availability of precursors (chemistry) and also on the altitude (temperature, mixing, downward transport, precursors). The maximum can occur in winter/early spring (Oltmans et al., 2004, 2006, 2007; Gros et al., 1998; Scheel et al., 1990), in spring, or in spring/summer (Scheel et al., 1997; Felipe-Soteloa et al., 2006; Scheel, 2003; Schuepbach et al., 2001; Varotsos et al., 2001; Sunwoo and Carmichael, 1994; Ahammed et al., 2006, and many other papers). A complex interplay of photochemical and dynamical processes controls the main features of surface ozone variations (Lelieveld and Dentener, 2000) and the shape of the seasonal cycle (Oltmans et al., 1992; Monks, 2000). An earlier classification of the surface ozone seasonal cycles for European sites was performed by Esser (1993) and confirmed by the results of the TOR-2 project. This classification was based on a priori information of the pollution and local meteorological conditions at the observational site and hence can be considered to have some degree of subjectivity. Moreover, it was noted that even for neighboring locations the shape of the seasonal variations can be different (e.g. Felipe-Soteloa et al., 2006).

A prominent feature, namely the spring maximum in Northern Hemisphere mid-latitudes that is well visible in background observatories is still subject to research (Scheel et al., 1997; EMEP Assessment, 2004; Schuepbach et al., 2001; Li et al., 2002). A re-analysis of historical records confirms the existence of the spring maximum in earlier years (Linvill et al., 1980; Monks, 2000; Nolle et al., 2005), although clearly the shape of the cycle is sensitive to pollution conditions. For example, Zvyaginsev (2004) analyzing the 1976-1995 Hohenpeissenberg data (for which spring and summer maxima are separated) showed that the summer maximum changes more strongly than the spring maximum. Scheel et al. (2003) reported that at the Zugspitze for more polluted years the seasonal maximum is observed later in the year.

Most of the aspects of the surface ozone seasonality, and its spring maximum in particular, can be found in the review of Monks (2000). He mentions a number of issues that need further work, namely the relative contributions of dynamical (STE) and photo-chemical processes, the relationship between ozone and precursor cycles, and the role of long-range transport versus in-situ photochemical production.

Whereas most overview papers consider the seasonal cycle on the basis of a priori information for given observation sites, our contribution to better understanding the surface ozone seasonality is solely based on a statistical analysis of observed ozone time series and of corresponding model output. We use data from the extra-tropics around the globe to gain insight into average seasonal and diurnal changes, thereby trying to attribute the roles of the relevant underlying processes. Unlike most studies we do include the diurnal cycle in our considerations. This point is very important as diurnal variations bear information on local pollution conditions and boundary layer dynamics. In particular, the rate of the afternoon ozone growth is defined by the local precursor levels, and the formation of the morning minimum is defined by the properties of the underlying surface and intensity of the temperature inversion. Moreover, formation of the breeze-type (with morning diurnal maximum) or mountaintype (with night diurnal maximum) shape of the diurnal cycle is defined by the dynamics of the boundary layer. Thus the inclusion of diurnal variations into the analysis can help to distinguish more clearly the different regimes of the surface ozone variations and to identify the processes driven by sunlight. After applying a non-biased statistical approach to the observations, we do virtually the same to the model output.

Our paper has the following structure: In Sect. 2 we discuss the observational data used for the analysis and give a brief overview of the ECHAM5/MESSy1 modelling system. In Sect. 3 the analytical technique is discussed and Sect. 4 presents the results of the classification of the observational data and the model output, and provides a discussion of the obtained results and the cluster inter-comparison. Conclusions are presented in Sect. 5.

\section{Data}

For our climatological study we use surface ozone records of at least 10 years duration from non-tropical latitudes (excluded is the belt between $25^{\circ} \mathrm{S}$ and $25^{\circ} \mathrm{N}$ ). The hourly data were obtained from the EMEP project (www.emep.int) and the World Data Centre for Greenhouse Gases (http: //gaw.kishou.go.jp). A total of 114 time series are used. Because the majority of the datasets are obtained from EMEP, the total data set has a geographical bias to Europe. For the Southern Hemisphere, where the coverage is very poor, some 8 year records had to be used. The data are presented in $\mathrm{nmol} / \mathrm{mol}$. The entire set of sites is listed in Table 1 including the site coordinates, the altitude, an identifier and the cluster membership as deduced below. All of the used datasets have confirmed quality (e.g. Hjellbrekke and Solberg, 2003). The variability of the monthly mean mixing ratio calculations (annual standard deviation of the monthly means for each hour of the day) is estimated to be between $2 \%$ and $7 \%$ (Zvyagintsev, 2004) for each particular location.

The comparison with model output is performed using the results of the 3-D atmospheric chemistry general circulation model ECHAM5/MESSy1 (http://www. messy-interface.org), which - in the applied setup - simulates consistently the chemistry and dynamics of the atmosphere between the Earth's surface and the upper stratosphere/lower mesosphere (approx. $80 \mathrm{~km}$ ). The data used here are the results of the S1 simulation presented by Jöckel 
Table 1. List of the sites used for the analysis. Negative latitudes denote the Southern Hemisphere, negative longitudes denote western longitudes.

\begin{tabular}{|c|c|c|c|c|c|c|}
\hline & Site code & Site title & latitude & longitude & altitude, $\mathrm{m}$ & Cluster number \\
\hline 1 & SPO789S40 & South Pole & -89.98 & -24.8 & 2810 & 1 \\
\hline 2 & MCM777S40 & McMurdo / Arrival Height & -77.8 & 166.77 & 50 & 1 \\
\hline 3 & MNM224N00 & Minamitorishima & 24.3 & 153.97 & 8 & 1 \\
\hline 4 & BMW432N40 & Tudor Hill & 32.37 & -64.65 & 30 & 1 \\
\hline 5 & RYO239N00 & Ryori & 39.03 & 141.82 & 260 & 1 \\
\hline 6 & CHA446N00 & Chalk River & 46.07 & -77.4 & 184 & 1 \\
\hline 7 & ALG447N00 & Algoma & 47.03 & -84.38 & 411 & 1 \\
\hline 8 & ELA449N00 & Experimental Lakes Area & 49.67 & -93.72 & 369 & 1 \\
\hline 9 & IE0031R & Mace Head & 53.17 & -9.5 & 15 & 1 \\
\hline 10 & GB0015R & Strath Vaich Dam & 57.73 & -4.77 & 270 & 1 \\
\hline 11 & NO0048R & Voss & 60.6 & 6.53 & 500 & 1 \\
\hline 12 & NO0039R & Kårvatn & 62.78 & 8.88 & 210 & 1 \\
\hline 13 & NO0015R & Tustervatn & 65.83 & 13.92 & 439 & 1 \\
\hline 14 & FI0022R & Oulanka & 66.32 & 29.4 & 310 & 1 \\
\hline 15 & SE0013R & Esrange & 67.88 & 21.07 & 475 & 1 \\
\hline 16 & NO0042G & Spitsbergen - Zeppelinfjell & 78.9 & 11.88 & 474 & 1 \\
\hline 17 & AT0033R & Stolzalpe bei Murau & 47.13 & 14.2 & 1302 & 2 \\
\hline 18 & CZ0003R & Kosetice & 49.58 & 15.08 & 534 & 2 \\
\hline 19 & DK0031R & Ulborg & 56.28 & 8.43 & 10 & 2 \\
\hline 20 & EGB444N00 & Egbert & 44.23 & -79.78 & 253 & 2 \\
\hline 21 & EST451N00 & Esther & 51.67 & -110.2 & 707 & 2 \\
\hline 22 & FI0009R & Utö & 59.78 & 21.38 & 7 & 2 \\
\hline 23 & FI0017R & Virolahti & 60.53 & 27.69 & 4 & 2 \\
\hline 24 & FUN132N00 & Funchal & 32.65 & -16.88 & 58 & 2 \\
\hline 25 & GB0002R & Eskdalemuir & 55.31 & -3.2 & 243 & 2 \\
\hline 26 & GB0006R & Lough Navar & 54.44 & -7.87 & 126 & 2 \\
\hline 27 & GB0013R & Yarner Wood & 50.6 & -3.71 & 119 & 2 \\
\hline 28 & GB0014R & High Muffles & 54.33 & -0.81 & 267 & 2 \\
\hline 29 & GB0031R & Aston Hill & 52.5 & -3.03 & 370 & 2 \\
\hline 30 & GB0033R & Bush & 55.86 & -3.21 & 180 & 2 \\
\hline 31 & GB0035R & Great Dun Fell & 54.68 & -2.44 & 847 & 2 \\
\hline 32 & GB0036R & Harwell & 51.57 & -1.32 & 137 & 2 \\
\hline 33 & GB0037R & Ladybower Res. & 53.4 & -1.75 & 420 & 2 \\
\hline 34 & GB0038R & Lullington Heath & 50.79 & 0.18 & 120 & 2 \\
\hline 35 & GB0043R & Narberth & 51.23 & -4.7 & 160 & 2 \\
\hline 36 & KEJ444N00 & Kejimkujik & 44.43 & -65.2 & 127 & 2 \\
\hline 37 & LV0010R & Rucava & 56.22 & 21.22 & 5 & 2 \\
\hline 38 & NO0001R & Birkenes & 58.38 & 8.25 & 190 & 2 \\
\hline 39 & NO0041R & Osen & 61.25 & 11.78 & 440 & 2 \\
\hline 40 & NO0043R & Prestebakke & 59 & 11.53 & 160 & 2 \\
\hline 41 & NO0045R & Jeloeya & 59.43 & 10.6 & 5 & 2 \\
\hline 42 & PL0004R & Leba & 54.75 & 17.53 & 2 & 2 \\
\hline 43 & PL0005R & Diabla Gora & 54.15 & 22.07 & 157 & 2 \\
\hline 44 & PT0004R & Monte Velho & 38.08 & -8.8 & 43 & 2 \\
\hline 45 & SAT448N00 & Saturna & 48.78 & -123.13 & 178 & 2 \\
\hline 46 & SE0002R & Roervik & 57.42 & 11.93 & 10 & 2 \\
\hline 47 & SE0012R & Aspvreten & 58.8 & 17.38 & 20 & 2 \\
\hline 48 & SE0032R & Norra-Kvill & 57.82 & 15.57 & 261 & 2 \\
\hline 49 & SE0035R & Vindeln & 64.25 & 19.77 & 225 & 2 \\
\hline 50 & SK0006R & Starina & 49.05 & 22.27 & 345 & 2 \\
\hline 51 & SK0007R & Topolniky & 47.96 & 17.86 & 113 & 2 \\
\hline 52 & USI354S0 & Ushuaia & -54.85 & -68.32 & 18 & 2 \\
\hline 53 & AT0002R & Illmitz & 47.77 & 16.77 & 117 & 3 \\
\hline 54 & AT0030R & Pillersdorf bei Retz & 48.72 & 15.94 & 315 & 3 \\
\hline
\end{tabular}


Table 1. Continued.

\begin{tabular}{|c|c|c|c|c|c|c|}
\hline & Site code & Site title & latitude & longitude & altitude, $\mathrm{m}$ & Cluster number \\
\hline 55 & AT0042R & Heidenreichstein & 48.88 & 15.05 & 570 & 3 \\
\hline 56 & AT0045R & Dunkelsteinerwald & 48.37 & 15.55 & 320 & 3 \\
\hline 57 & AT0046R & Gaenserndorf & 48.33 & 16.73 & 161 & 3 \\
\hline 58 & AT0047R & Stixneusiedl & 48.05 & 16.68 & 240 & 3 \\
\hline 59 & BE0001R & Offagne & 49.88 & 5.2 & 430 & 3 \\
\hline 60 & BE0032R & Eupen & 50.63 & 6 & 295 & 3 \\
\hline 61 & BE0035R & Vezin & 50.5 & 4.99 & 160 & 3 \\
\hline 62 & $\mathrm{CH} 0002 \mathrm{R}$ & Payerne & 46.82 & 6.95 & 510 & 3 \\
\hline 63 & $\mathrm{CH} 0003 \mathrm{R}$ & Taenikon & 47.48 & 8.9 & 540 & 3 \\
\hline 64 & DE0001R & Westerland & 54.93 & 8.31 & 12 & 3 \\
\hline 65 & DE0002R & Langenbruegge & 52.8 & 10.76 & 74 & 3 \\
\hline 66 & DE0004R & Deuselbach & 49.76 & 7.05 & 480 & 3 \\
\hline 67 & DE0007R & Neuglobsow & 53.17 & 13.03 & 62 & 3 \\
\hline 68 & DE0008R & Schmuecke & 50.65 & 10.77 & 937 & 3 \\
\hline 69 & DE0009R & Zingst & 54.43 & 12.73 & 1 & 3 \\
\hline 70 & DE0012R & Bassum & 52.85 & 8.7 & 52 & 3 \\
\hline 71 & DE0017R & Ansbach & 49.25 & 10.58 & 481 & 3 \\
\hline 72 & DE0026R & Ueckermuende & 53.75 & 14.07 & 1 & 3 \\
\hline 73 & DE0035R & Lueckendorf & 50.83 & 14.77 & 490 & 3 \\
\hline 74 & DK0032R & Frederiksborg & 55.97 & 12.33 & 10 & 3 \\
\hline 75 & DK0041R & Lille Valby & 55.69 & 12.13 & 10 & 3 \\
\hline 76 & GB0032R & Bottesford & 52.93 & -0.82 & 32 & 3 \\
\hline 77 & GB0034R & Glazebury & 53.46 & -2.47 & 21 & 3 \\
\hline 78 & GB0039R & Sibton & 52.29 & 1.46 & 46 & 3 \\
\hline 79 & IT0004R & Ispra & 45.8 & 8.63 & 209 & 3 \\
\hline 80 & KPS646N00 & K-puszta & 46.97 & 19.55 & 125 & 3 \\
\hline 81 & LT0015R & Preila & 55.35 & 21.07 & 5 & 3 \\
\hline 82 & NL0009R & Kollumerwaard & 53.33 & 6.28 & 1 & 3 \\
\hline 83 & NL0010R & Vredepeel & 51.54 & 5.85 & 28 & 3 \\
\hline 84 & PL0002R & Jarczew & 51.82 & 21.98 & 180 & 3 \\
\hline 85 & SE0011R & Vavihill & 56.02 & 13.15 & 175 & 3 \\
\hline 86 & SK0004R & Stara Lesna & 49.15 & 20.28 & 808 & 3 \\
\hline 87 & TKB236N30 & Tsukuba & 36.05 & 140.13 & 25 & 3 \\
\hline 88 & LIS638N00 & Lisboa / Gago Coutinho & 38.77 & -9.13 & 105 & 4 \\
\hline 89 & SI0033R & Kovk & 46.13 & 15.11 & 600 & 4 \\
\hline 90 & SI0031R & Zarodnje & 46.43 & 15 & 770 & 4 \\
\hline 91 & $\mathrm{CH} 0004 \mathrm{R}$ & Chaumont & 47.05 & 6.98 & 1130 & 4 \\
\hline 92 & $\mathrm{CH} 0005 \mathrm{R}$ & Rigi & 47.07 & 8.47 & 1030 & 4 \\
\hline 93 & AT0044R & Graz Platte & 47.11 & 15.47 & 651 & 4 \\
\hline 94 & AT0040R & Masenberg & 47.35 & 15.88 & 1170 & 4 \\
\hline 95 & AT0032R & Sulzberg & 47.53 & 9.93 & 1020 & 4 \\
\hline 96 & AT0004R & St.Koloman & 47.65 & 13.2 & 851 & 4 \\
\hline 97 & HPB647N00 & Hohenpeissenberg & 47.8 & 11.02 & 985 & 4 \\
\hline 98 & DE0003R & Schauinsland & 47.91 & 7.91 & 1205 & 4 \\
\hline 99 & AT0041R & Haunsberg & 47.97 & 13.02 & 730 & 4 \\
\hline 100 & AT0043R & Forsthof & 48.11 & 15.92 & 581 & 4 \\
\hline 101 & DE0005R & Brotjacklriegel & 48.82 & 13.22 & 1016 & 4 \\
\hline 102 & SK0002R & Chopok & 48.93 & 19.58 & 2008 & 4 \\
\hline 103 & CZ0001R & Svratouch & 49.73 & 16.03 & 737 & 4 \\
\hline 104 & PL0003R & Sniezka & 50.73 & 15.73 & 1603 & 4 \\
\hline 105 & NWR440N40 & Niwot Ridge & 40.03 & -105.53 & 3022 & 5 \\
\hline 106 & SI0032R & Krvavec & 46.3 & 14.54 & 1740 & 5 \\
\hline 107 & JFJ646N00 & Jungfraujoch & 46.55 & 7.98 & 3578 & 5 \\
\hline 108 & AT0038R & Gerlitzen & 46.69 & 13.92 & 1895 & 5 \\
\hline
\end{tabular}


Table 1. Continued.

\begin{tabular}{lllrrrr}
\hline & Site code & Site title & latitude & longitude & altitude, $m$ & Cluster number \\
\hline 109 & AT0034G & Sonnblick & 47.05 & 12.96 & 3106 & 5 \\
110 & AT0037R & Zillertaler Alpen & 47.14 & 11.87 & 1970 & 5 \\
111 & NMY770S00 & Neumayer & -70.65 & -8.25 & 42 & 6 \\
112 & SYO769S2 & Syowa Station & -69 & 39.58 & 29 & 6 \\
113 & BAR541S00 & Baring Head & -41.42 & 174.87 & 85 & 6 \\
114 & BRW471N40 & Barrow & 71.32 & -156.6 & 8 & 6 \\
\hline
\end{tabular}

et al. (2006). In this simulation the model dynamics has been weakly nudged in the free troposphere/lower stratosphere (up to $100 \mathrm{hPa}$ ) towards ECMWF operational analysis data, in order to follow the actual meteorology. For our analysis it is important to mention that most of the ozone precursor emissions have been prescribed for each year as monthly average fluxes of the year 2000. This could cause some discrepancy while comparing multi-annual averages of the measurements and the model output.

The model ECHAM5/MESSy1 has been compared to the other GCMs and to observations (Jöckel et al., 2006), showing that the main processes are correctly described in the model. For instance, the stratospheric contribution in the model is $393 \pm 25 \mathrm{Tg}\left(\mathrm{O}_{3}\right) \mathrm{y}^{-1}$ and the dry deposition is $780 \pm 25 \mathrm{Tg}\left(\mathrm{O}_{3}\right) \mathrm{y}^{-1}$, which is for both processes at the lower end of the ranges presented by Stevenson et al. (2006) in the model inter-comparison experiment.

The provided model output has a time resolution of $5 \mathrm{~h}$, yielding an hourly resolved diurnal cycle every 5 days. From the $\sim 2.8^{\circ} \times \sim 2.8^{\circ}$ gridded model output ozone time series at the positions of the observational sites have been subsampled. Due to the rather coarse model grid, some neighbouring sites are located in the same model grid box. Each model grid box, however, was taken into consideration only once. Thus, the number of the used model time series (72) is smaller than the actual number of sites (114) which are used for the analysis. Since the model is formulated on hybrid "terrain following" vertical layers, the lowest model level has been selected. This is feasible, since boundary layer processes, such as for instance dry deposition, are important at most of the measurement sites, with the exception of some elevated sites, at which often free tropospheric air is sampled. Even for these cases, it was not possible to find a nonarbitrary, strict criterion to justify sampling at higher model levels.

The model output covers the period from 1998 to 2005 and does not overlap completely with the measurement periods. In addition to the ozone time series, also the simulated stratospheric ozone tracer $\left(\mathrm{O}_{3}^{(s)}\right)$ has been sampled (available from 2000 onward) in the same way. This tracer indicates the ozone content that originates from the stratosphere. In the analysis this information is used to estimate the contribution of the STE to the observed mixing ratios at the surface. The
STE is one of the processes controlling surface ozone variability and competing to chemical production/destruction. In some cases low average mixing ratios can be accompanied by rather high stratospheric contributions being annulated for example by local destruction. Thus the obtained numbers are more indicative (qualitative) than quantitative.

\section{Statistical analysis}

Long-term trends of surface ozone mixing ratios can differ from site to site (e.g. in the range from $+2.6 \pm 0.6 \% / y e a r$ to $-1.4 \pm 0.7 \%$ /year as reported by Virgarzan, 2004), which increases the uncertainty in the estimated means. To reduce possible biases and to unify the datasets, all time series were first de-trended by subtracting the incline of a linear regression in time. This provides statistical uniformity of the seasonal variations, i.e. the averaging for each annual period should give the same mean within the range of uncertainties. The trend correction is between $-0.8 \mathrm{nmol} / \mathrm{mol} / \mathrm{year}$ and $+1.4 \mathrm{nmol} / \mathrm{mol} /$ year and turned out to be rather different even for close locations. This issue of the trends, however, will not be discussed further in the present analysis.

For each particular location (measurement site or corresponding model grid box) we calculated 24 averaged seasonal cycles, corresponding to each hour of the day for the whole measurement/simulation period. The result is a matrix giving the average seasonal variation for a given time of a day and the diurnal cycle for each month simultaneously for each considered location, $\mathrm{O}_{3, i}(h, m)$. Here $i$ is the index of the measurement/simulated data location, $h$ is the local time in hours and $m$ is the month of the year. The number $\mathrm{N}$ of matrices, which were subjected to classification, is 114/72 for the measurements/model output, respectively. To obtain seasonal uniformity, the data for the Southern Hemisphere were shifted by 6 months. The model output has been shifted from universal time (UTC) to local time based on longitude information in order to synchronize it with the observations.

The term cluster analysis (first used by Tryon, 1939) comprises a number of different algorithms and methods for grouping objects with similar properties into respective groups in a way that the degree of association between two objects is maximal if they belong to the same group and minimal otherwise. Given the above, cluster analysis can be used 


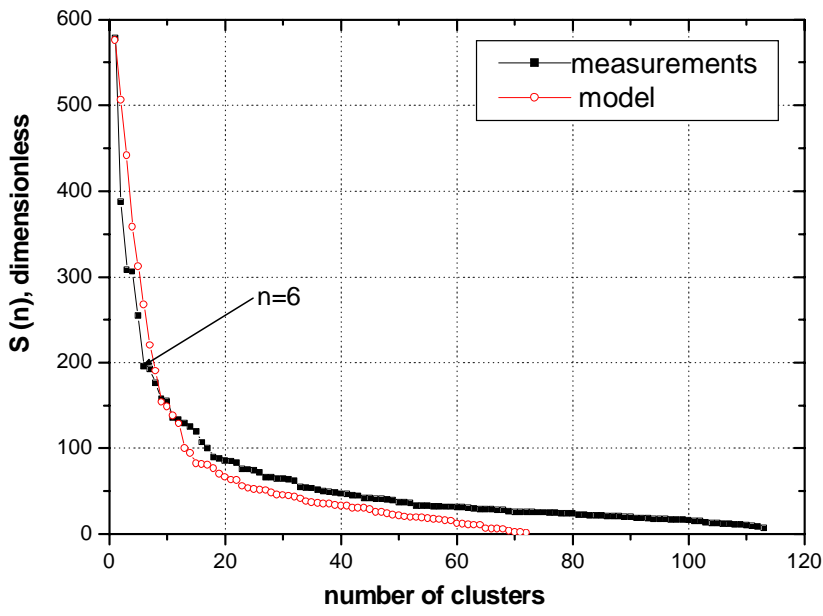

Fig. 1. Changes of the total dispersion in the process of the agglomeration. The optimal number of clusters for the measurements is shown in the graph $(n=6)$ and corresponds to the point of the first strong change of $S(n)$. For the model results the changes of $S(n)$ are rather smooth, thus the number of clusters was selected to be the same as for the measurements.

to discover structures in data without a priori information on the data properties (Hill and Lewicki, 2006).

Basically there are two different clustering algorithms (Everitt, 1993), namely hierarchical and non-hierarchical clustering. The purpose of the hierarchical clustering is to join objects into successively larger clusters, using some measure of similarity or distance. All the classified objects are considered at each step of the hierarchical clustering and the process is determined by the construction of an agglomeration (discrimination) tree. This approach is usually used when the number of clusters is unknown. A detailed overview of hierarchical classification (including agglomeration and discrimination techniques) can be found in Gordon (1987). Hierarchical clustering is for instance often used in air transport classification (Cape et al., 2000; Colette et al., 2005).

Unlike the hierarchical clustering procedure applied here, non-hierarchical clustering (e.g. the k-means algorithm) requires that the number of clusters is already known and that the objects are distributed between those (Moody et al., 1991). This algorithm is widely used in cases where a priori information on the nature of the measurements is available. An example is the classification of aerosol types (Omar et al., 2005). Since we have no a priori information on the number of the particular patterns in our data, this method is not applicable here.

The agglomeration hierarchical procedure begins by initializing $\mathrm{N}$ singleton clusters (in our case one seasonaldiurnal matrix). Then the two closest clusters are merged to form a single cluster. This process is repeated until one cluster remains. Results of the agglomeration process can be different depending on the applied measure of the dissimilar- ities (similarities) and distances between objects when forming the clusters. Normalization of the input data can also impact the results of classification slightly and it is usually performed to provide an equal weight to all the variables used for classification and to decrease the effect of the data scatter.

In this paper a squared Euclidean distance is used as a measure of distance between the objects $i$ and $j$ :

$\operatorname{dist}^{2}\left(\mathrm{O}_{3, i}, \mathrm{O}_{3, j}\right)=\sum_{h, m}\left(\mathrm{O}_{3, i}(h, m)-\mathrm{O}_{3, j}(h, m)\right)^{2}$,

where the sum is over $24 \mathrm{~h}(h)$ and 12 months $(m)$.

As an agglomeration rule the average linkage within groups is used. It takes into consideration the mean distance between all possible inter- or intra-cluster pairs, unlike the average linkage method (Beaver and Palazoglu, 2006), where only the distance between the cluster averages is taken into consideration. The average distance between all pairs in the resulting cluster is minimised, $\min \left(d_{i i}\right)$, while the average distance between all the pairs in two different clusters is maximised, $\max \left(d_{i j}\right)$ :

$d(i, j)=\frac{1}{n_{i} n_{j}} \sum_{s=1}^{n_{i}} \sum_{k=1}^{n_{j}} \operatorname{dist}^{2}\left(\mathrm{O}_{3, s}, \mathrm{O}_{3, k}\right)$,

where $\mathrm{n}_{i}$ and $\mathrm{n}_{j}$ are the number of the objects in the clusters $i$ and $j$. Since we have a rather small number of objects, the application of this agglomeration method allows us to obtain the maximum homogeneity within the clusters. In spite of the fact that the best results can be obtained with the Ward method, it is not applicable in our case as it tends to force the clusters to have similar sizes, which is not appropriate in the case of spatially inhomogeneous information.

In the agglomeration process the total distance between cluster centres and cluster members is determined at each step, representing a total dispersion $\mathrm{S}$ of the system

$S(n)=\sum_{i=1}^{n} \sum_{j=1}^{n_{j}} \operatorname{dist}^{2}\left(\mathrm{O}_{3, j}, \mathrm{O}_{3, i}\right)$,

where $\mathrm{O}_{3, i}$ is a centre of the cluster $i, \mathrm{O}_{3, j}$ are the members of the cluster $i, n_{j}$ is the number of the elements in the cluster $i$ and $n$ is the total number of clusters. The dispersion $S(n)$ rises monotonously and reaches its maximum when all the vectors are unified in a single cluster $(n=1)$. The appropriate number of clusters is defined by the point of the extreme growth rate of $S(n)$. The choice of the number of clusters is quite flexible if the growth rate of $S(n)$ has no distinct extreme. In the case of a normal distribution of classified vectors, $S(n)$ changes smoothly and the choice of the number of clusters can be rather subjective (e.g. in the case of the model output).

As stated above, we apply hierarchical agglomeration clustering to the seasonal-diurnal matrices of the measurements and of the model output. Figure 1 shows $S(n)$ for both cases (measurements and model output) simultaneously. For 
cluster 1

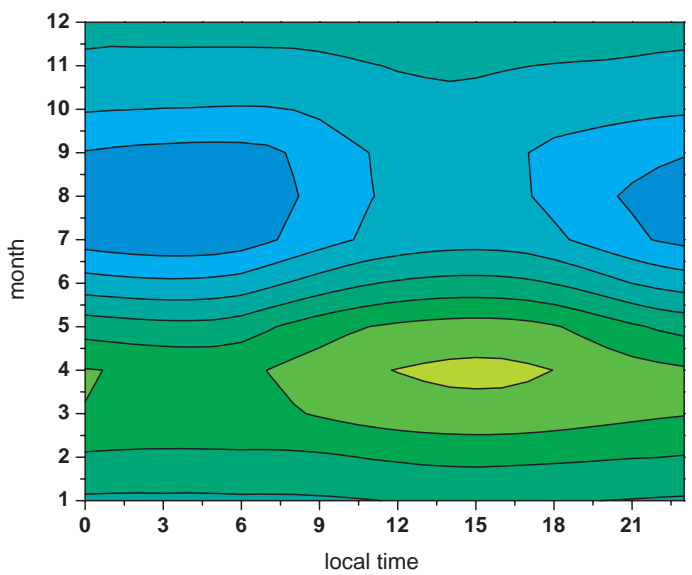

cluster 3

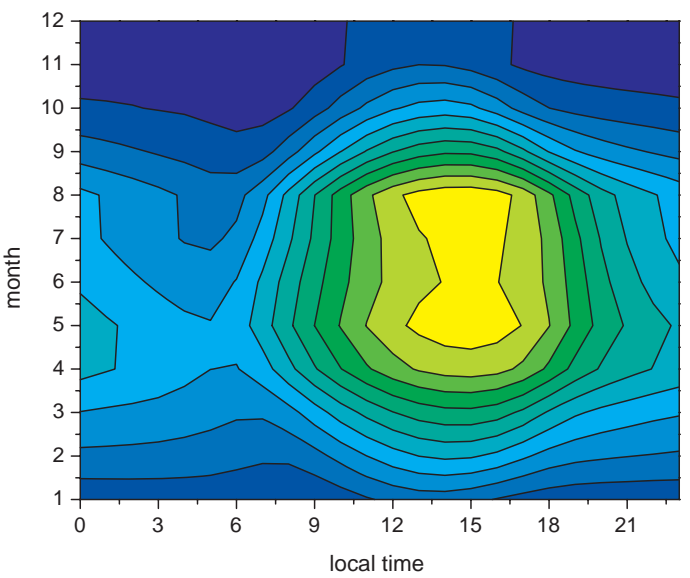

cluster 5

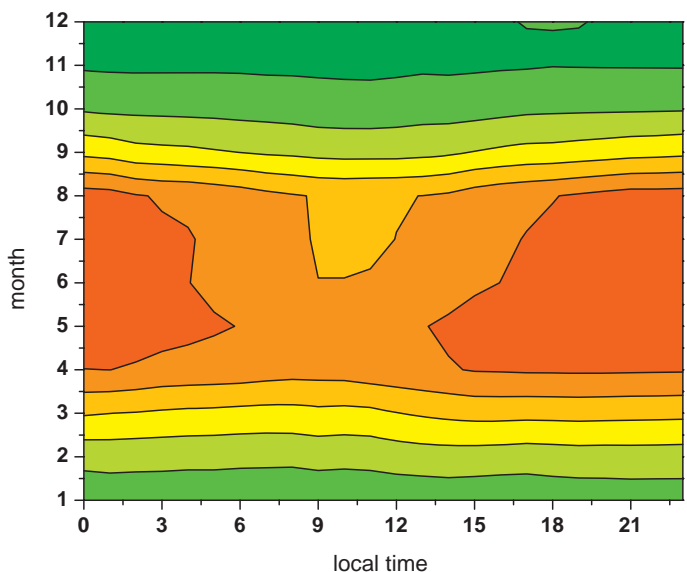

cluster 2

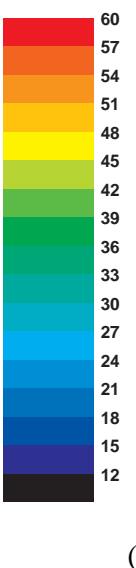

(b)

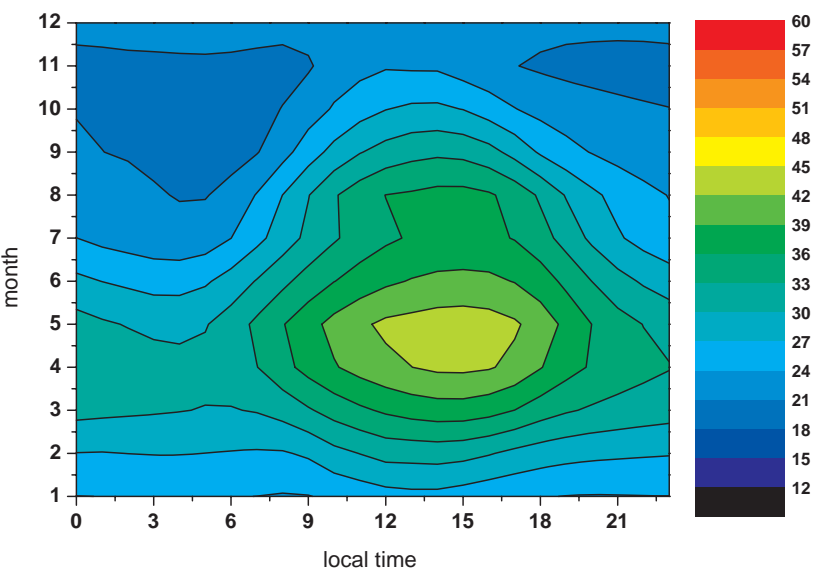

cluster 4

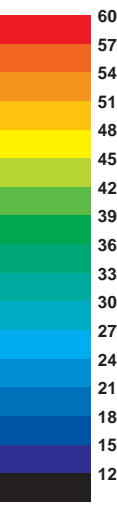

(d)

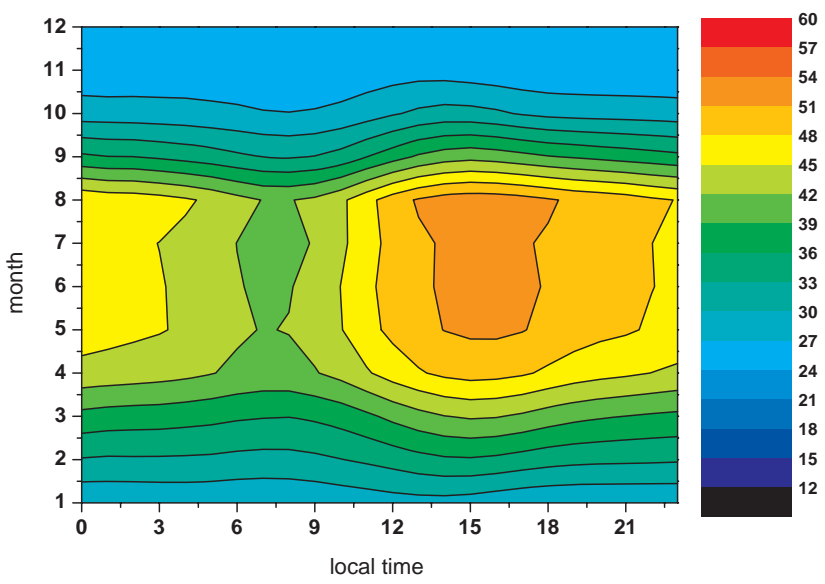

cluster 6
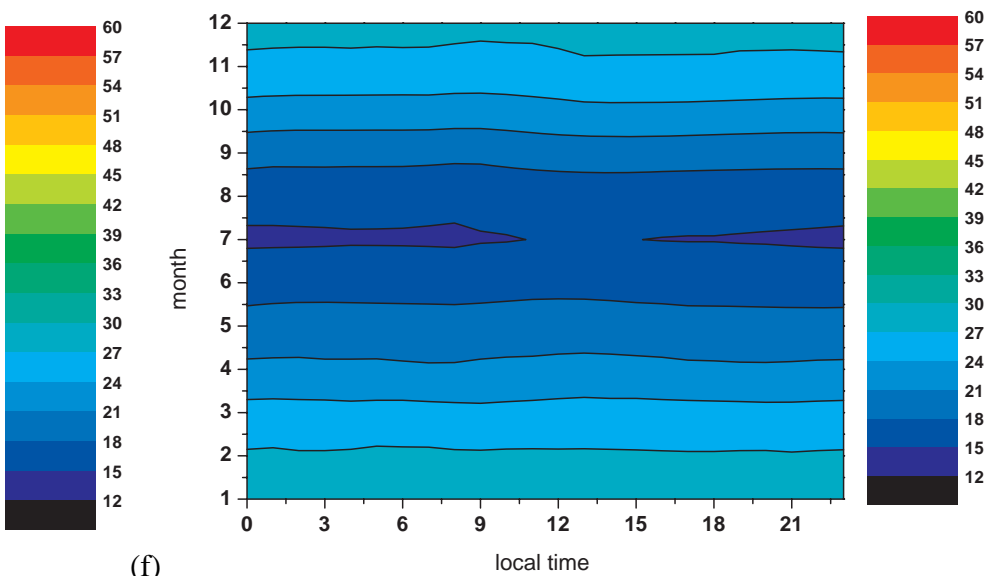

Fig. 2. Seasonal - diurnal cycles for the 6 clusters representing 114 observed time series as described in the text. The colour scale shows the mixing ratio in nmol/mol. The following clusters are identified: (a) - clean background; (b) - rural; (c) - semi-polluted non-elevated; (d) semi-polluted semi-elevated; (e) - elevated and (f) - polar/remote.

observational data agglomeration in 6 clusters corresponds to the strong gradient of the total dispersion. At the same time the relative change of $S(n)$ in the agglomeration of the model data is nearly stationary. Thus, the number of the model clusters (MC) was selected to be 6 , i.e. the same as for the measurements. The cluster membership was defined at the 

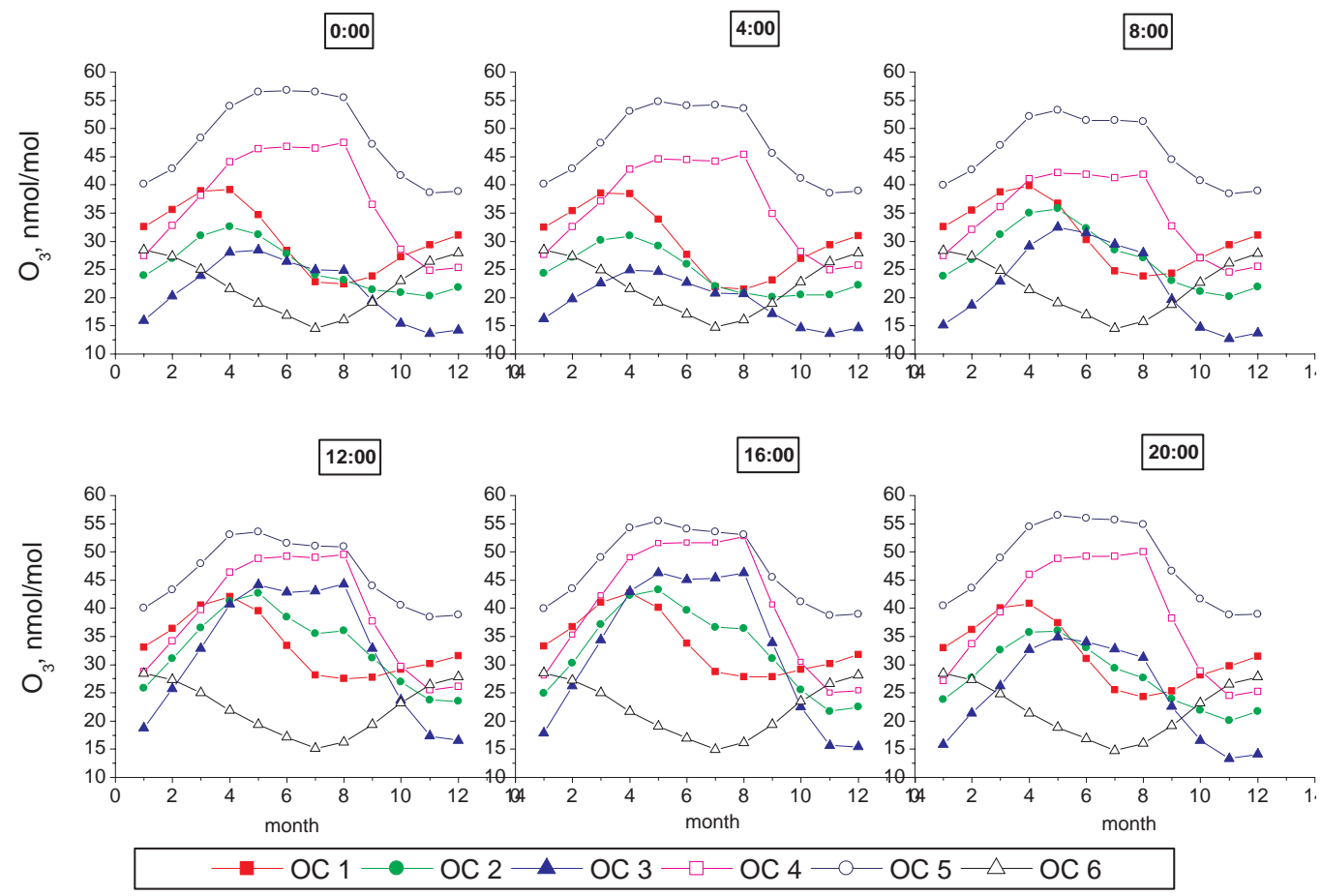

Fig. 3. Seasonal cycle of the surface ozone mixing ratio in different measurement clusters for selected hours of the day (the data obtained as a subset of the full picture presented in Fig. 2). The mixing ratio scale is the same in all graphs to show the differences between the clusters and to reflect their diurnal changes.

corresponding step of the agglomeration procedure. Average mixing ratios (cluster centres) and their standard deviation were calculated as an average of the seasonal-diurnal cycles included in each cluster (average of the cluster members). The procedure was applied to the measurements and to the simulated data independently.

\section{Results}

4.1 Classes of the observed surface ozone seasonal-diurnal cycles

The 6 typical classes (centres of the corresponding clusters) identified by the cluster analysis of the average seasonaldiurnal matrices of 114 sites are visualized in Fig. 2. The statistics of the obtained clusters for the observations and the model output are summarised in Table 2. It should be kept in mind that all estimates given in the text have a range in the order of one standard deviation listed in Table 2.

Cluster 1 (Fig. 2a) referred to as OC1 (Observational Cluster 1) is characterized by a pronounced spring maximum (March-April). The values range from $21 \mathrm{nmol} / \mathrm{mol}$ to $43 \mathrm{nmol} / \mathrm{mol}$. The months of the seasonal maximum are nearly the same for any time of the day (Fig. 3). The maximum amplitude (difference between daily maximum and daily minimum) of the diurnal cycle is observed in JulyAugust (up to $7.0 \mathrm{nmol} / \mathrm{mol}$ ) and is rather small. It may be explained by a combination of local chemistry (providing weak daily production) and boundary layer dynamics (colder nights with stronger inversions and hence enhanced deposition at the surface). It can be seen (Fig. 2a) that in $\mathrm{OC} 1$ the night/early morning mixing ratios in August are the lowest throughout the year. In winter the amplitude of the diurnal variations is less than $1 \mathrm{nmol} / \mathrm{mol}$ and the absolute mixing ratios are around $30 \mathrm{nmol} / \mathrm{mol}$. The maximum amplitude of the seasonal variations is observed close to the time of the diurnal minimum $(17 \mathrm{nmol} / \mathrm{mol})$. It should be mentioned that the variations of the seasonal amplitude for different hours are less than $20 \%$ of its maximal magnitude. Such a regime of surface ozone variations is often reported for background/rural sites, not only in the extra tropics (e.g. Scheel et al., 1997; EMEP Assessment, 2004; Oltmans et al., 2006; Sunwoo et al., 1994), but also at some tropical locations (Ahammed et al., 2006). A comparison of the properties of $\mathrm{OC} 1$ with literature data indicates that sites in this cluster are unpolluted/remote and can be considered as representative for background conditions. Indeed, the geographic locations of the sites of this cluster (Fig. 4, Table 1) confirm this result. 
Table 2. Statistical information of the observational and model clusters. One $\sigma$ shows a standard deviation range in the estimate of the clusters centres (Figs. 2, 5, 7) as an average of $\mathrm{N}$ cluster members. Each range is representative for 288 values.

\begin{tabular}{|c|c|c|c|c|c|c|c|c|}
\hline $\mathrm{OC}$ & $\begin{array}{l}\text { No. of } \\
\text { sites }\end{array}$ & $\begin{array}{l}\text { One } \sigma \text { of } \\
\text { OC centres: } \\
\text { range, } \\
\text { (average), } \\
\mathrm{nmol} / \mathrm{mol}\end{array}$ & $\begin{array}{l}\text { Identified } \\
\text { type (OC) }\end{array}$ & $\begin{array}{l}\text { Mostly } \\
\text { over- } \\
\text { lapping } \\
\text { MC }\end{array}$ & $\begin{array}{l}\text { No. } \\
\text { of the } \\
\text { grid } \\
\text { boxes }\end{array}$ & $\begin{array}{l}\text { One } \sigma \text { of nmol/mol } \\
\text { MC centres: } \\
\text { range, } \\
\text { (average), }\end{array}$ & $\begin{array}{l}\text { Comment } \\
\text { on MC }\end{array}$ & $\begin{array}{l}\text { One } \sigma \text { of } \\
\text { MC-stratospheric } \\
\text { centres: } \\
\text { range, } \\
\text { (average), } \\
\text { nmol/mol }\end{array}$ \\
\hline \#1 & 16 & $\begin{array}{l}2.5-7.9 \\
(4.6)\end{array}$ & $\begin{array}{l}\text { clean } \\
\text { back- } \\
\text { ground }\end{array}$ & $\# 1$ & 18 & $\begin{array}{l}2.1-8.6 \\
(4.6)\end{array}$ & & $\begin{array}{l}0.4-2.1 \\
(1.2)\end{array}$ \\
\hline$\# 2$ & 36 & $\begin{array}{l}2.6-8.0 \\
(2.5)\end{array}$ & rural & $\# 2$ & 30 & $\begin{array}{l}3.5-12.1 \\
(5.6)\end{array}$ & & $\begin{array}{l}0.4-2.1 \\
(1.2)\end{array}$ \\
\hline \#3 & 35 & $\begin{array}{l}2.4-8.3 \\
(4.7)\end{array}$ & $\begin{array}{l}\text { semi- } \\
\text { polluted } \\
\text { non- } \\
\text { elevated }\end{array}$ & $\# 3$ & 15 & $\begin{array}{l}1.0-9.3 \\
(3.8)\end{array}$ & & $\begin{array}{l}0.2-1.6 \\
(0.7)\end{array}$ \\
\hline \#4 & 17 & $\begin{array}{l}1.8-5.2 \\
(3.4)\end{array}$ & $\begin{array}{l}\text { semi- } \\
\text { polluted } \\
\text { semi- } \\
\text { elevated }\end{array}$ & & & & & \\
\hline \#5 & 6 & $\begin{array}{l}1.0-6.2 \\
(2.6)\end{array}$ & elevated & & & & & \\
\hline \#6 & 4 & $\begin{array}{l}2.3-5.7 \\
(4.1)\end{array}$ & $\begin{array}{l}\text { polar- } \\
\text { remote }\end{array}$ & \#6 & 6 & $\begin{array}{l}0.4-5.8 \\
(2.4)\end{array}$ & $\begin{array}{l}\text { southern- } \\
\text { hemispheric }\end{array}$ & $\begin{array}{l}0.2-1.8 \\
(0.8)\end{array}$ \\
\hline \multicolumn{3}{|c|}{ included in $\mathrm{OC} \# 5$} & & $\# 4$ & 1 & 0 & $\begin{array}{l}\text { Niwot } \\
\text { Ridge }\end{array}$ & 0 \\
\hline \multicolumn{3}{|c|}{ included in $\mathrm{OC} \# 1$ and \#2 } & & $\# 5$ & 2 & $\begin{array}{l}0-6.6 \\
(1.9)\end{array}$ & $\begin{array}{l}\text { island } \\
\text { locations }\end{array}$ & $\begin{array}{l}0.0-2.1 \\
(0.6)\end{array}$ \\
\hline
\end{tabular}

A more complex shape of the cluster averaged seasonaldiurnal variations is observed in OC2 (Fig. 2b). Average mixing ratios in OC2 are similar to those in OC1 (19$44 \mathrm{nmol} / \mathrm{mol}$ ), while the shape of the seasonal cycle is different. At night it is characterized by a pronounced spring maximum in April, which is shifted to May for daytime hours (Fig. 2). A secondary seasonal maximum is formed in August during the day (Fig. 3). The spring maximum of OC2 is lower than that of the background $\mathrm{OC} 1$ at night (up to $8 \mathrm{nmol} / \mathrm{mol}$ ) and nearly equals it during daytime. At the same time the ozone mixing ratios in $\mathrm{OC} 2$ in winter are always (on average $9 \mathrm{nmol} / \mathrm{mol}$ ) lower than that of OC1. This probably points to a higher activity of the chemical processes in OC2 in comparison with $\mathrm{OC} 1$, both destruction and production. Assuming that $\mathrm{OC} 2$ is more polluted than $\mathrm{OC} 1$, the lower seasonal maximum at night may be explained by ozone destruction through reaction with NOx. This is supported by the highest differences between these clusters which are observed during the winter months. Higher values are observed in OC2 during daytime hours due to more efficient ozone production. Seasonal variations similar to those in OC2 have been reported for non-elevated rural sites, either clean or semi-polluted. The maximum amplitude of the diurnal cycle of OC2 is observed in August (up to $16 \mathrm{nmol} / \mathrm{mol}$ ) which is nearly 2 times larger than in background cluster OC1. In winter it does not exceed $5 \mathrm{nmol} / \mathrm{mol}$. The maximum amplitude of the seasonal cycle is observed at $16 \mathrm{~h}$ local time $(22 \mathrm{nmol} / \mathrm{mol})$. Depending on the time of the day, the amplitude of the seasonal cycle varies from $10 \mathrm{nmol} / \mathrm{mol}$ for early morning hours up to its maximum. These characteristics of the OC2 seasonal-diurnal variations in comparison with literature information (TOR-2 Final Report, 2003; Fiore et al., 2003; Felipe-Soteloa et al., 2006; Monks, 2000) suggest that this cluster is characteristic of weakly polluted non-elevated sites (mainly rural). As can be seen in Fig. 4, the sites of OC2 are situated in Northern Europe and the mid-latitudes of the USA, mainly in the regions close to seas and on islands (Fig. 4). Also one of the southern hemispheric sites appears in this cluster (Ushuaia) due to the fact that average levels at this site are comparable with those in $\mathrm{OC} 2$, while the individual shape of the seasonal cycle is different and is characterised by a wide winter-spring maximum. This can be considered as an artefact of our approach, as it tends to merge seasonal-diurnal matrices in one cluster by trying to minimize the difference inside the cluster, and hence unifying members with minimum mixing ratio differences.

In comparison to the background cluster $\mathrm{OC} 1$, in cluster 3 (OC3), changes of the shape of the seasonal cycle are more 

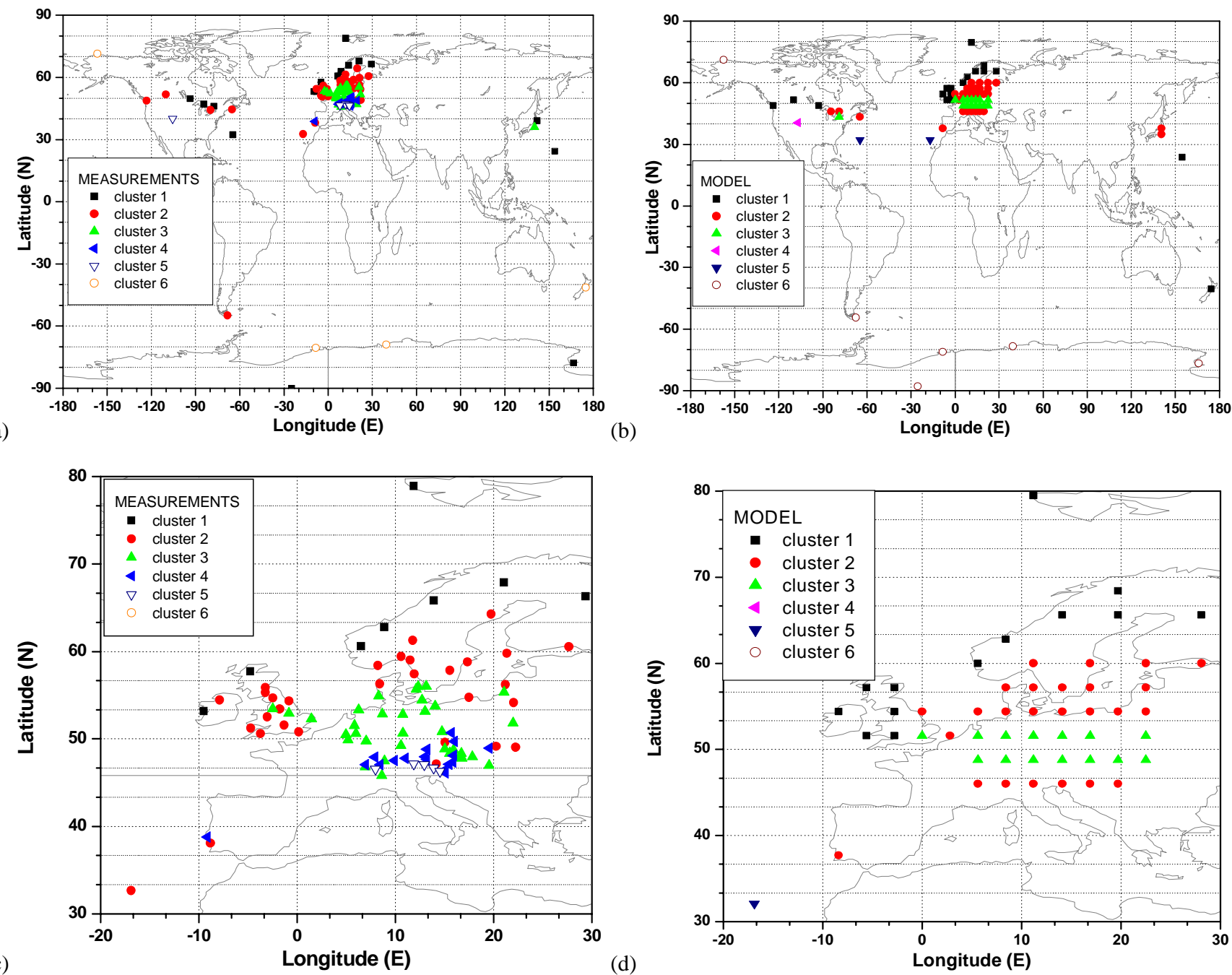

Fig. 4. Spatial distribution of the measurement sites of different clusters (a, c). The clusters obtained for the ECHAM5/MESSy 1 output are also presented on the maps $(\mathbf{b}, \mathbf{d})$. For the model, the points are placed to the centre of the grid-box covering the measurement sites. In the lower panel (c-d) Europe is shown in more detail.

pronounced. Average mixing ratios in OC3 range between 12 and $47 \mathrm{nmol} / \mathrm{mol}$ with minimal values of $9 \mathrm{nmol} / \mathrm{mol}$ and of $7 \mathrm{nmol} / \mathrm{mol}$ lower than in $\mathrm{OC} 1$ and $\mathrm{OC} 2$, respectively. In contrast, the maximum mixing ratios are only $3-4 \mathrm{nmol} / \mathrm{mol}$ higher than in OC1 and OC2. OC3 is characterized by a wide spring-summer seasonal maximum (Fig. 3c). At night a spring "shoulder" of the seasonal maximum is more pronounced, while during daytime the spring and summer maxima are comparable. It should be noted that during winter the ozone mixing ratios in $\mathrm{OC} 3$ are substantially lower than those in OC1 and OC2 at any time of the day (up to $17 \mathrm{nmol} / \mathrm{mol}$ and $8 \mathrm{nmol} / \mathrm{mol}$, respectively), while the summer nighttime mixing ratios in OC3 are comparable to the corresponding mixing ratios in $\mathrm{OC} 1$ and $\mathrm{OC} 2$. The summer daytime mixing ratios in OC3 are higher than those in OC1 and OC2 (up to $19 \mathrm{nmol} / \mathrm{mol}$ and $10 \mathrm{nmol} / \mathrm{mol}$, respectively). The spring maximum in OC3 is observed in April-May. Diurnal max- ima and minima are observed at the same time as in OC2 at any season. The amplitude of the seasonal cycle varies from $11 \mathrm{nmol} / \mathrm{mol}$ at $5 \mathrm{a} . \mathrm{m}$. local time to $31 \mathrm{nmol} / \mathrm{mol}$ around 3 p.m., which exceeds nearly 1.5 times the corresponding amplitude of the seasonal cycle in OC2. The amplitude of the diurnal cycle varies from $3 \mathrm{nmol} / \mathrm{mol}$ in December to $27 \mathrm{nmol} / \mathrm{mol}$ in August. Substantial variations (both seasonal and diurnal) of the surface ozone mixing ratios in OC3, the decrease during winter to values lower than the background and a substantial increase in summer, especially during daytime, point to high activity of photo-chemical processes in this cluster: strong ozone destruction by reaction with NO in winter and efficient ozone production in summer. The substantially higher deviations of the ozone mixing ratios in OC3 from $\mathrm{OC} 1$ in comparison with similar differences between $\mathrm{OC} 1$ and $\mathrm{OC} 2$ indicate that the surface ozone variations observed in OC3 may be representative for more polluted sites 
in comparison to OC1 and OC2 (e.g. Varotsos et al., 2001). For some sites included in OC3 (e.g. IT0004R, KPS646N00 and some others) the value of the summer maximum can exceed the spring maximum, especially for daytime hours, indicating strong photochemical ozone production. The locations of the sites of OC3 on the map (Fig. 4) show that they are likely affected by a variety of pollution sources.

OC4 (Fig. 2d) has a structure of the seasonal-diurnal cycle similar to that of OC3. Notwithstanding, the ozone levels in OC4 are higher than in OC2 or OC 3 for all seasons and all times of the day (Fig. 3), i.e. in the range of $24-53 \mathrm{nmol} / \mathrm{mol}$. This holds in winter and at night (at least $3 \mathrm{nmol} / \mathrm{mol}$ excess over OC2 and at least $11 \mathrm{nmol} / \mathrm{mol}$ excess over OC 3 ). It is unlikely that the sites of this cluster are less polluted as far as OC2 represents rural conditions. The presence of pollution is confirmed by the fact that the winter mixing ratios in $\mathrm{OC} 4$ are lower than that of OC1. During the period from November till February mixing ratios at any time of the day are from $2 \mathrm{nmol} / \mathrm{mol}$ to $6 \mathrm{nmol} / \mathrm{mol}$ lower in OC4 than in OC1. In contract to $\mathrm{OC} 3$, in $\mathrm{OC} 4$ the seasonal maximum at night is not very sharp and occurs during spring and summer. During the day the summer maximum is more pronounced and usually exceeds the spring maximum (Fig. 3). In comparison with the background $\mathrm{OC} 1$ spring maximum, the maximum in OC4 is two months delayed, which again indicates a higher pollution level for OC4. A similar effect was reported by Scheel et al. (2003), who showed that at Zugspitze for the more polluted years the seasonal maximum is shifted to later months. The amplitude of the diurnal cycle in OC4 varies from $1 \mathrm{nmol} / \mathrm{mol}$ in December up to $11.0 \mathrm{nmol} / \mathrm{mol}$ in $\mathrm{Au}-$ gust, which is $5 \mathrm{nmol} / \mathrm{mol}$ lower than in OC2 and by more than a factor of 2 less than in OC3. This means that either daily ozone production plays a less important role in OC4 in comparison with $\mathrm{OC} 2$ and $\mathrm{OC} 3$, or that the diurnal variations in OC4 are less sensitive to diurnal changes of the vertical mixing and local photochemistry. The comparison of the altitude ranges of sites included in OC3 and OC4, respectively, shows that the first group $(1 \mathrm{~m}-937 \mathrm{~m}$ a.s.l., average $207 \mathrm{~m}$ a.s.l.) is less elevated than the second group (105$2008 \mathrm{~m}$, average of $952 \mathrm{~m}$ a.s.l.). The amplitude of the seasonal variations in OC4 varies from $17 \mathrm{nmol} / \mathrm{mol}$ at 7 a.m. to $28 \mathrm{nmol} / \mathrm{mol}$ at $4 \mathrm{p} . \mathrm{m}$. Summarising the features of OC4 discussed above and comparison with the seasonal cycles in various publications (Oltmans at al., 2006, Fiore et al., 2003; Scheel et al., 2003) lead us to the conclusion that OC4 represents the semi-polluted semi-elevated sites. This is confirmed by Fig. 4 .

The average seasonal-diurnal cycle in the observational cluster 5 (OC5, Fig. 1e) is characterized by a broad springsummer maximum with higher nighttime values. The average mixing ratios in OC5 are in the range of $38-57 \mathrm{nmol} / \mathrm{mol}$ and they are the highest among all clusters. At night the maxima of the seasonal variations are not distinguishable (Fig. 3), while during the day a double peak structure is present. The difference between seasonal maxima is very weak. Mixing ratios observed in OC5 exceed those in all other clusters during all seasons and all times of the day, especially in winter. The excess of OC5 over the background OC1 in winter is at least $6 \mathrm{nmol} / \mathrm{mol}$. The amplitude of the diurnal cycle varies from $0.3 \mathrm{nmol} / \mathrm{mol}$ in December to $6.0 \mathrm{nmol} / \mathrm{mol}$ in June-July, which is the period of highest insolation. These values are substantially lower than in the other clusters, except for OC6, where the diurnal cycle is absent. Since the maximum occurs at night, the diurnal cycle can be driven by boundary layer dynamics, while photochemical production only plays a minor role. The amplitude of the seasonal cycle varies from $14 \mathrm{nmol} / \mathrm{mol}$ at 9 a.m. up to $18 \mathrm{nmol} / \mathrm{mol}$ between 10 p.m. and 12 p.m. The rather stable high mixing ratios and the seasonal variations are nearly insensitive to the time of the day (with a slight growth at night) and most likely correspond to the surface ozone regime observed at mountain sites (Oltmans at al., 2006; Fiore et al., 2003; Scheel et al., 2003; Schuepbach et al., 2001; Tarasova et al., 2003). Presenting the members of OC5 on the map indeed shows elevated locations (Fig. 4). The summary in Table 2 shows that there are 6 locations included in OC5, all with elevations of more than $1700 \mathrm{~m}$ a.s.l. (Table 1).

The structure of the observational cluster 6 (OC6) demonstrates how sites with different mechanisms influencing the seasonal and diurnal variations can appear in the same cluster due to comparable mixing ratio levels and due to similarities of the seasonal variations. OC6 includes 4 sites, situated in the coastal zone of the Arctic (Barrow) and Antarctica (Neumayer and Syowa Station) and a site in New Zealand (Baring Head) (Fig. 4). The mixing ratios in OC6 range between 14 and $29 \mathrm{nmol} / \mathrm{mol}$. Three other sites of the Southern Hemisphere are considered in the analysis, namely South Pole and McMurdo, which are in OC1, and Ushuaia in cluster OC2. These sites have higher mixing ratios and they are assigned to the other clusters with more appropriate levels. In fact the shape of the seasonal-diurnal variations is quite similar for all southern hemispheric locations. OC6 is characterized by a pronounced winter (local June-July) seasonal maximum. Note that southern hemispheric data were 6 months shifted prior to the analysis. The winter seasonal maximum is observed at all times of the day and in absence of diurnal variations (Fig. 2). Such a shape of the seasonal cycle is reported for the majority of the mid- and high-latitude locations of the Southern Hemisphere, in particular for Cape Point, Cape Grim, South Pole and others (Oltmans et al., 2006; 2007; Scheel et al., 1990; Gros et al., 1998). The diurnal variations in this cluster are very weak and do not exceed $1 \mathrm{nmol} / \mathrm{mol}$. This absence of diurnal variations indicates that the surface ozone variability is controlled by the processes with timescales longer than a day. The amplitude of the seasonal cycle in OC6 reaches $14 \mathrm{nmol} / \mathrm{mol}$ and does not depend on the time of the day. The high stability of ozone at the sites in OC6 probably shows that atmospheric transport can be more important for these sites than local fast photochemistry. The surface ozone variation represented by OC6 occurs at those 
locations where photochemical activity is weak because of low precursor levels and/or because of the low levels of sunlight and/or because chemical destruction does not play a role in winter (such as in polar regions or on remote islands). The map (Fig. 4) shows that OC6 comprises the sites situated in the polar (or close to polar) coastal zones of Antarctica, New Zealand and Alaska. It is likely that photochemical processes are more important at these locations for the formation of the seasonal minimum through ozone destruction in springsummer (reactions with bromine compounds), while photochemical production is very unlikely. The seasonal maximum at these locations is more plausibly connected with transport processes, both vertical motions (STE) and horizontal advection.

4.2 Classes of model simulated surface ozone seasonaldiurnal cycles

To compare the features of the clusters obtained for the measurement sites with the results from the global model simulation, we applied the same technique to the sampled model output at the grid boxes covering the measurement locations. For the model results we applied the hierarchical clustering procedure and stopped the agglomeration algorithm at 6 clusters to compare the obtained cluster centres with those obtained for the measurements. It should be noted (see Table 2 for details) that the majority of the grid boxes are covered by 3 large clusters, while two clusters contain only one or two grid boxes.

Similar to the measurements, the mean seasonal-diurnal cycles of the model clusters (MC) are presented in Fig. 6. As additional information used for the interpretation of the studied variations, the mean stratospheric contribution calculated for each model cluster is presented (Fig. 7). This parameter is used to indicate the role of stratosphere-to-troposphere transport and its changes throughout the year for each particular model cluster. Figure 7 a shows the stratospheric contribution in absolute values, while Fig. $7 \mathrm{~b}$ shows it in relative values to the average mixing ratio observed in the model clusters. It should be noted that these values are used only as a qualitative indication rather than a quantitative estimate. An excess of the relative contribution over $100 \%$ shows that in situ chemical destruction exceeds local production + stratospheric contribution. The maximum of the stratospheric contribution in absolute values is observed in February-March (Fig. 7a) depending on the cluster. Differences between February and March are usually within the range of uncertainty of the clusters' average (see last column of Table 2). Some errors can arise in these estimates due to the different time coverage of the considered data sets (1990-2004 for the measurements, 1998-2005 for the model output mixing ratios and 2000-2005 for the stratospheric contribution estimate).
The comparison of the main properties of the observational clusters and the ECHAM5/MESSy1 model clusters, respectively (Figs. 1 and 4), shows that the model reproduces the main classes of the observed variations reasonably well. The following classes are represented by the model: a cluster with a winter-early spring seasonal maximum and a less pronounced diurnal cycle (analogous to OC6); a cluster with a spring maximum and a well established diurnal cycle (analogous to $\mathrm{OC} 1$ ); a cluster with spring-summer maxima and a developed diurnal cycle (comparable to OC2 and OC3); a cluster with elevated mixing ratios (throughout the year), a pronounced seasonal spring maximum and a very weak diurnal cycle with an amplitude independent of the season (similar to OC5); and a cluster with a developed seasonal maximum in summer and a strong diurnal cycle. The last two regimes are likely to be similar to OC3 and OC4.

The model cluster 1 (MC1) by the shape of its seasonaldiurnal matrix is comparable to OC1. It contains 18 grid boxes. Mixing ratios range in $\mathrm{MC} 1$ from $20 \mathrm{nmol} / \mathrm{mol}$ to $40 \mathrm{nmol} / \mathrm{mol}$, which is close to the range of the mixing ratios in OC1 $(21-43 \mathrm{nmol} / \mathrm{mol})$ and OC2 $(19-44 \mathrm{nmol} / \mathrm{mol})$. The average seasonal-diurnal cycle in MC1 presented in Fig. 5a is characterised by the pronounced spring maximum in AprilMay. The seasonal maximum is observed in April during night and early morning hours, while for daytime the maximum is shifted to May (Fig. 6). This is one month later than in the background cluster $\mathrm{OC} 1$ and coincides with the timing of the seasonal maximum in the rural cluster OC2 (Fig. 8a). The deviation of the daily average mixing ratios in $\mathrm{MC} 1$ from those in OC2 (Fig. 9) shows that in winter the simulated mixing ratios are slightly higher (less than $2 \mathrm{nmol} / \mathrm{mol}$ ) than those in $\mathrm{OC} 2$, while in summer (June-August) they are up to $4 \mathrm{nmol} / \mathrm{mol}$ lower than in $\mathrm{OC} 2$. The summer mixing ratios in $\mathrm{MC} 1$ are close to those of $\mathrm{OC} 1$ and exceed them by less than $2 \mathrm{nmol} / \mathrm{mol}$. In general, the shape of the seasonaldiurnal matrix of $\mathrm{MC} 1$ is closer to that of $\mathrm{OC} 2$ than to that of OC1. The amplitude of the seasonal cycle in $\mathrm{MC} 1$ varies from $11 \mathrm{nmol} / \mathrm{mol}$ at night to its maximum of $17 \mathrm{nmol} / \mathrm{mol}$ at 5 p.m. This range is similar to that of OC1. The excess of the diurnal maximum in summer of about $5 \mathrm{nmol} / \mathrm{mol}$ and the winter deficit of around $10 \mathrm{nmol} / \mathrm{mol}$ in $\mathrm{MC} 1$ in comparison with $\mathrm{OC} 1$ indicate the overestimated contribution of photochemical production/destruction for the grid boxes in $\mathrm{MC} 1$. The amplitude of the diurnal cycle in $\mathrm{MC} 1$ varies from $1 \mathrm{nmol} / \mathrm{mol}$ in December-January to its maximum in JulyAugust (up to $11 \mathrm{nmol} / \mathrm{mol}$ ), which is a bit higher than that in OC1. The difference of the mixing ratios in $\mathrm{MC} 1$ and $\mathrm{OC} 1$ in winter is higher than the dispersion of the cluster centres and is likely caused by the above mentioned overestimated destruction. The stratospheric contribution in MC1 does not exceed $60 \%$ in winter and $10 \%$ in summer. The map showing the locations of the $\mathrm{MC} 1$ grid boxes indeed indicates unpolluted locations (in Fig. $4 \mathrm{MC} 1$ is mostly overlapping with OC1). 
model cluster 1

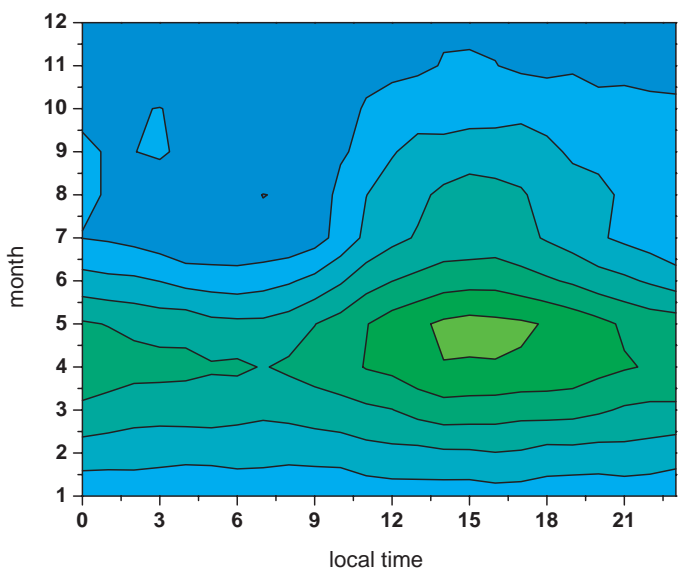

model cluster 3

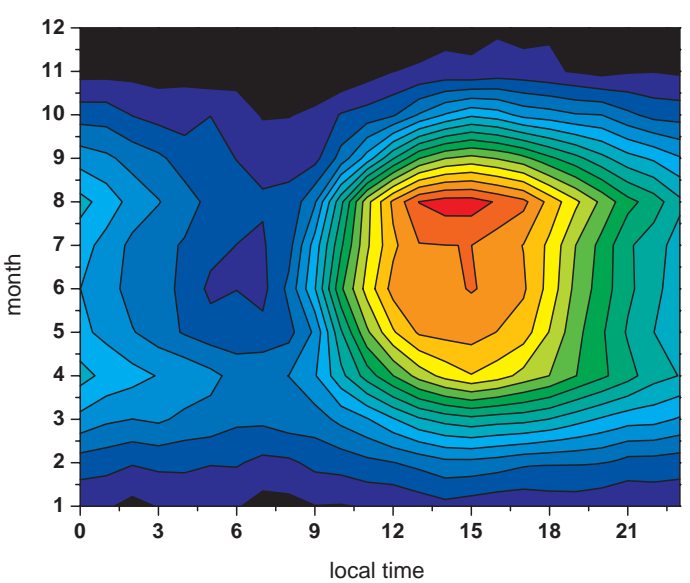

(c)

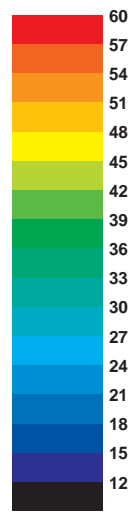

(b)

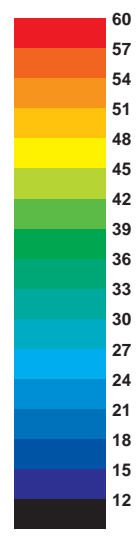

(d)

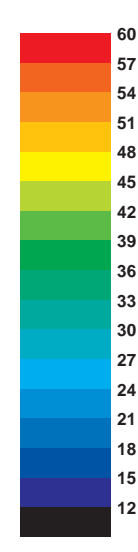

(f) model cluster 2

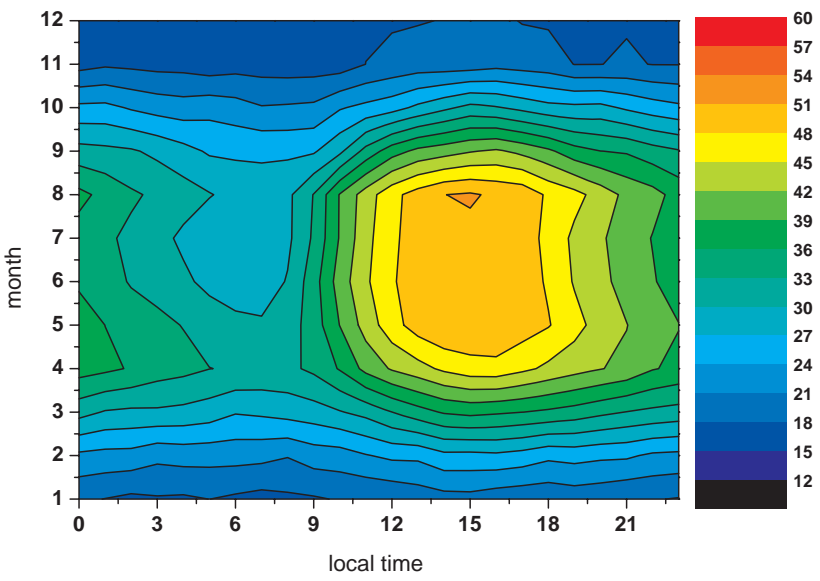

model cluster 4

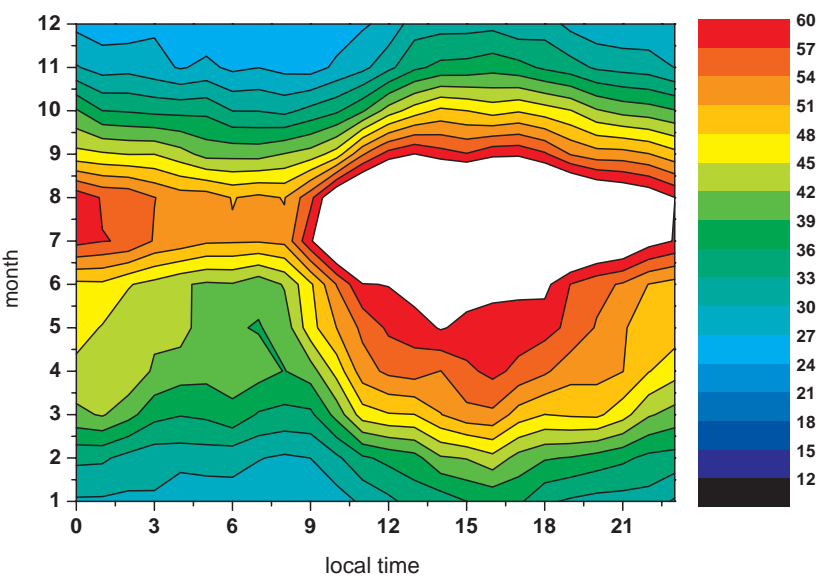

model cluster 6

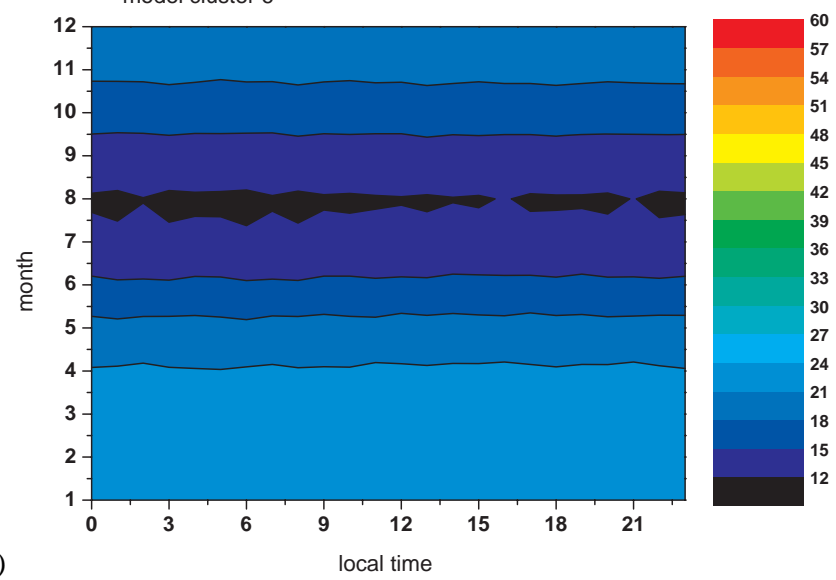

Fig. 5. Seasonal-diurnal ozone cycles for the 6 clusters of the ECHAM5/MESSy1 model output sub-sampled at the measurement sites. Colours and units are as in Fig. 2.

The model cluster 2 (MC2) by its absolute values (16$51 \mathrm{nmol} / \mathrm{mol}$ ) is closer to OC3 (Fig. 5b) than to OC2. Around half of the grid boxes are contained in this cluster (30 of 72). This cluster is characterized by a broad spring-summer max- imum. As can be seen in Fig. 6 such a shape of the seasonal cycle is present at all times of the day, while it is more likely to show a double peak structure for nighttime hours. It is interesting to note that during the day absolute mixing ratios 

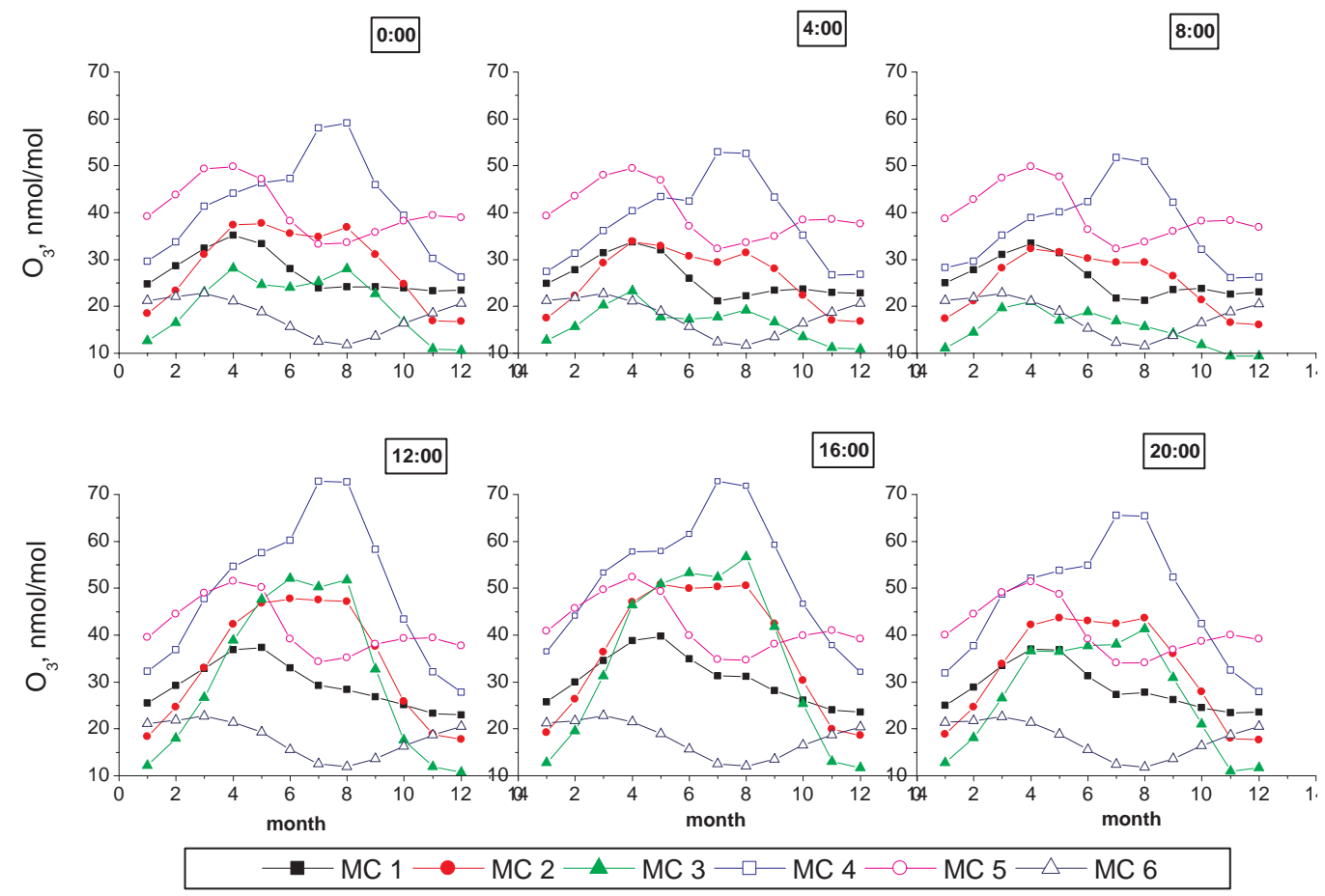

Fig. 6. Seasonal cycle of the surface ozone mixing ratio in different model clusters for selected hours of the day (the data obtained as a subset of the full picture presented in Fig. 5, similar to Fig. 3 for the measurements).

of the both (spring and summer) maxima grow (Fig. 6). This is similar to the diurnal development of the seasonal cycle in OC3 (Fig. 3). But unlike OC3, where during daytime the summer maximum gets more pronounced, the shape of the seasonal cycle in MC2 is similar for day and night (only the absolute values are growing). This likely implies that local photo-chemical production does not play a primary role and the production is of a more regional impact (the growth is provided by the growing "background" mixing ratios). The amplitude of the seasonal cycle varies from $16 \mathrm{nmol} / \mathrm{mol}$ at 7 a.m. to $32.9 \mathrm{nmol} / \mathrm{mol}$ at $2-3 \mathrm{p} . \mathrm{m}$. The maximum amplitude of the seasonal cycle in MC2 exceeds both corresponding values for OC2 and OC3. Comparison of MC2 and OC2 (Fig. 8b) shows that during summer not only the maximum, but also the minimum values are higher in MC2 than in OC2, e.g. in July-August the diurnal minimum is overestimated by around $5 \mathrm{nmol} / \mathrm{mol}$. Since nighttimes values can not be explained by overestimated production, this could indicate a positive bias of the simulated values in comparison to the measurements. Further checks did not reveal any systematic shift. The stratospheric contribution reaches its maximum in MC2 in March $(16.5 \mathrm{nmol} / \mathrm{mol})$ and it does not exceed $5 \mathrm{nmol} / \mathrm{mol}$ in summer. These values contribute up to $80 \%$ of the average mixing ratio in winter and up to $15 \%$ in summer. It is less plausible that the stratospheric contribution is overestimated in this cluster, causing a substantial deviation from OC2. The map (Fig. 4b, d) shows that MC2 covers a part of Northern Europe by a wide belt along the coast, the Alps, some mid-latitude rural sites of the USA and islands (Japan). Thus the possible reason for the elevated ozone mixing ratios in $\mathrm{MC} 2$ in comparison with $\mathrm{OC} 2$ is that $\mathrm{MC} 2$ covers semi-elevated and mountain locations. Since the model is formulated on terrain following vertical coordinates, it will represent to some extent elevated locations. This results in higher ozone mixing ratios in comparison to the measurements (where semi-elevated and mountain sites are separated into different clusters). This statement is also confirmed by a slight shift of the diurnal cycle in MC2 to later hours in comparison to $\mathrm{OC} 2$.

The model cluster 3 (MC3) has a mean seasonal-diurnal matrix similar to those of MC2 and OC3 (Fig. 5c) and is characterized by a wide spring-summer maximum. The range of the mixing ratios in MC3 is wider than those in MC1 and $\mathrm{MC} 2$ and amounts to $9-58 \mathrm{nmol} / \mathrm{mol}$. As for OC3, the seasonal cycle in MC3 changes during the day. For nighttime hours the spring and summer maxima are comparable. For daytime hours the spring maximum is not pronounced and the summer mixing ratios exceed the spring mixing ratios (April-May) by $6 \mathrm{nmol} / \mathrm{mol}$ (Fig. 6). This indicates local photochemical ozone production. The amplitude of the seasonal cycle strongly depends on the time of the day and varies from $10 \mathrm{nmol} / \mathrm{mol}$ at 6 a.m. to $47 \mathrm{nmol} / \mathrm{mol}$ at 2 p.m., 

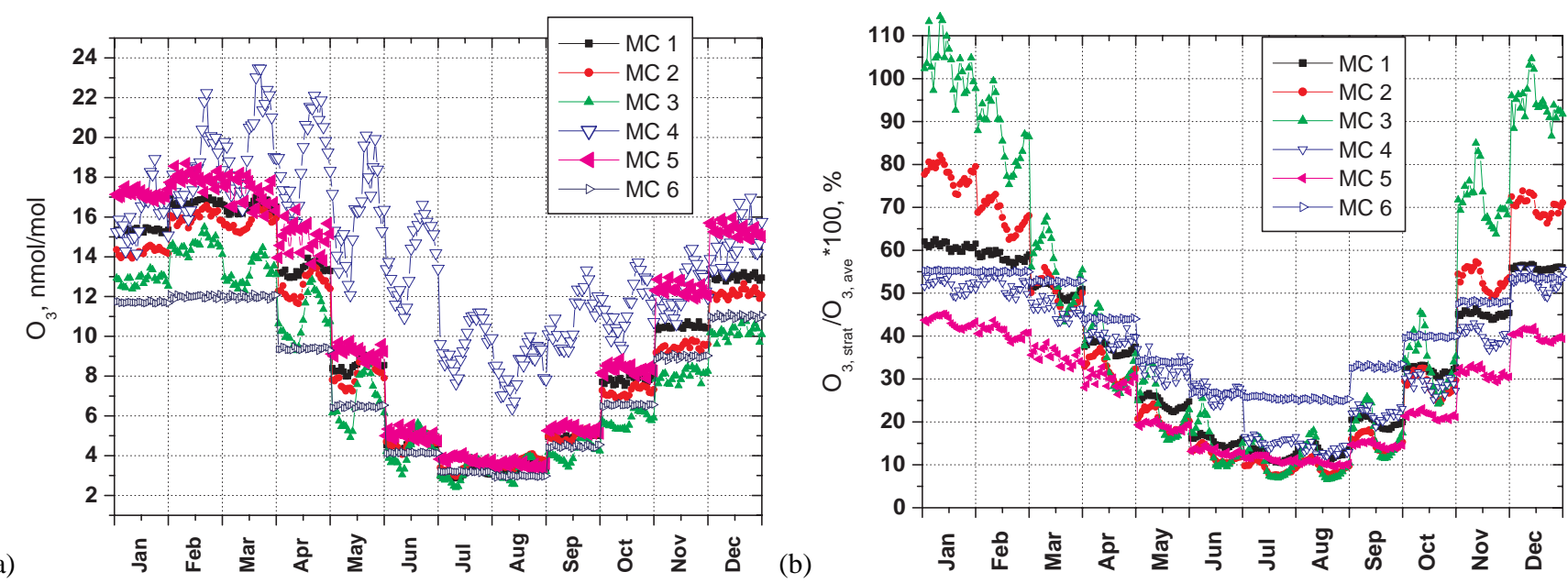

Fig. 7. Stratospheric contribution to the surface ozone averaged for each model cluster in absolute values (a) and as a relative contribution to the simulated mixing ratios (b). In the figure the averaged diurnal cycles are presented for every month. Error bars are not presented for the sake of visibility of the data and instead are summarized in Table 2.

(a)

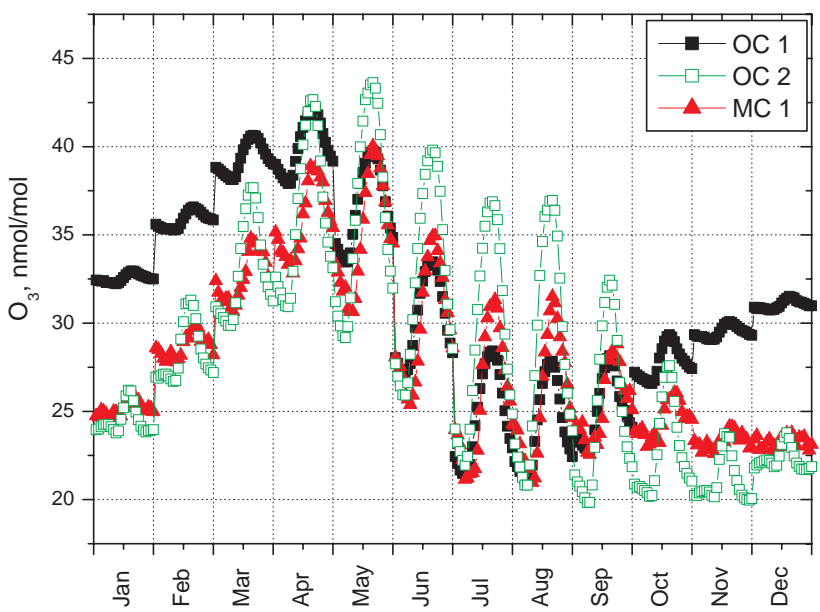

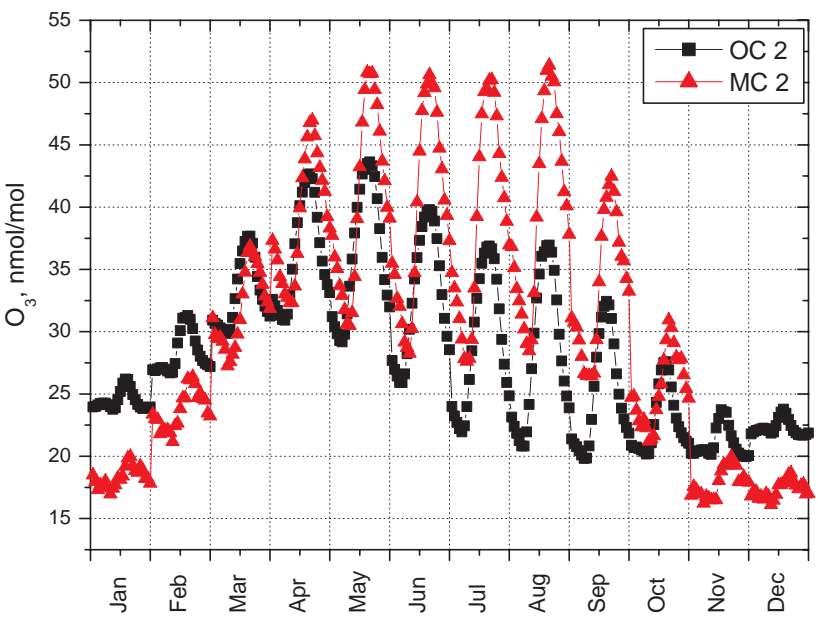

(b)

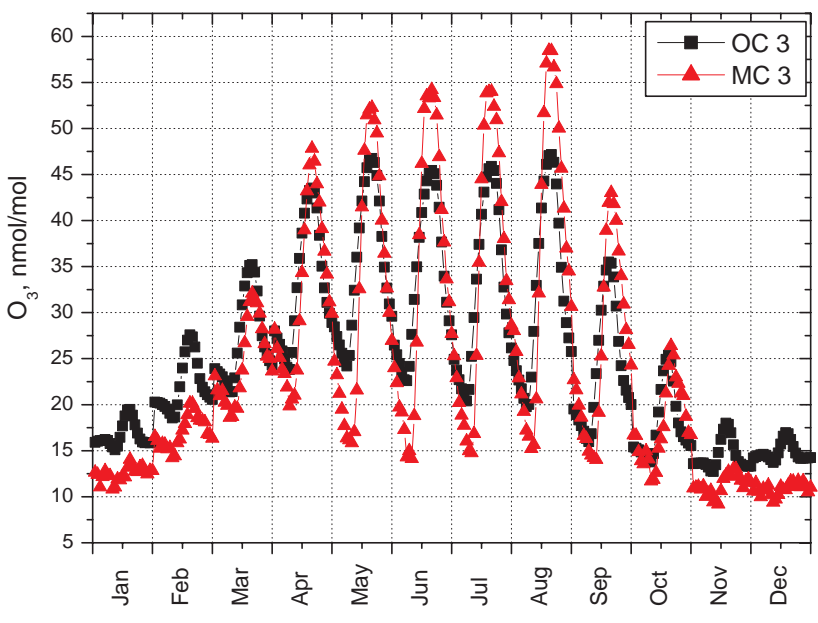

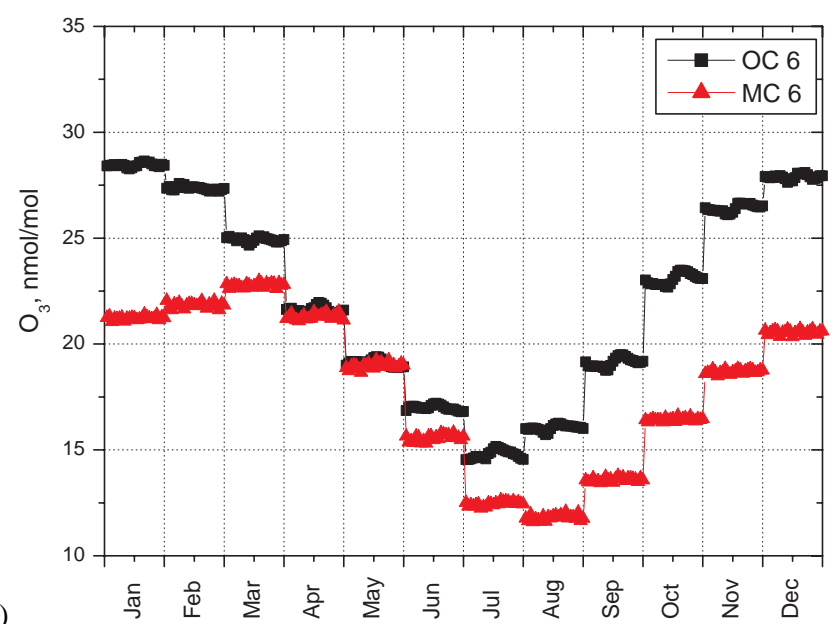

Fig. 8. Comparison of the seasonal-diurnal cycle between spatially overlapping clusters of the measurements and the model results as presented in Table 2. As in Fig. 7, the lines show average diurnal cycles for each month. 


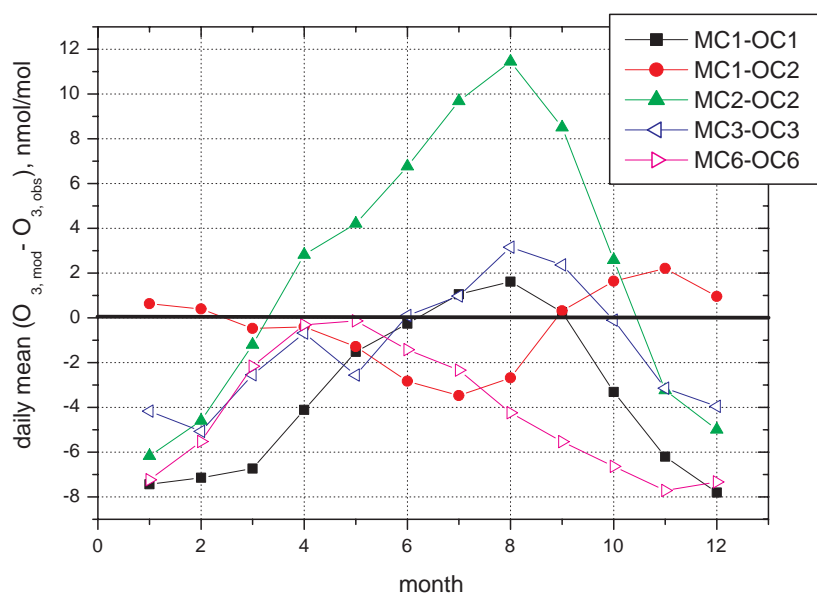

Fig. 9. Seasonal cycle of daily averaged difference between mostly or partly overlapping model and observation clusters.

indicating the connection of the seasonality with local photochemical activity. A strong production also causes strong diurnal variations in summer. Nevertheless, Fig. 8c demonstrates a quite good agreement between MC3 and OC3 in winter. Moreover, the daytime mean values support a comparison of MC3 and OC3 (Fig. 9), indicating that the model overestimate in summer is less than $4 \mathrm{nmol} / \mathrm{mol}$ and the maximum underestimation in the other seasons is $5 \mathrm{nmol} / \mathrm{mol}$. Taking into consideration the uncertainty of the cluster centres this comparison provides a good result. For both the model and measurement clusters (MC3 and OC3) the maximum of the diurnal variations is observed in August and reaches $43 \mathrm{nmol} / \mathrm{mol}$ and $27 \mathrm{nmol} / \mathrm{mol}$, respectively. Figure $7 \mathrm{~b}$ shows that the relative contribution of stratospheric ozone to the average mixing ratios exceeds $100 \%$ in winter, which means that the chemical ozone destruction exceeds the total production and the flux from the stratosphere. Therefore, the observed mixing ratios are even lower than the mixing ratios of the stratospheric tracer. The maximum overestimate of MC3 over OC3 is around $10 \mathrm{nmol} / \mathrm{mol}$ in summer at the diurnal maximum, while the simulated diurnal minima are less than $8 \mathrm{nmol} / \mathrm{mol}$ lower than those of the measurements. Taking into consideration the limitations of the global model and the difference in the covered periods, the agreement between MC3 and OC3 can be considered as rather good. The map (Fig. 4) of the cluster distribution shows that MC 3 contains 15 grid boxes covering the sites of Central Europe and rural sites in the USA. Since MC3 is centred in Central Europe, the problem of the elevation which impacts MC2 is not so critical in this cluster.

The model cluster 4 (MC4) presents a special case (Fig. 5d). This cluster consists of only one grid box, corresponding to Niwot Ridge, i.e. an elevated site in the USA. This cluster is characterised by the highest (among MC and OC) mixing ratios in the range of $24-73 \mathrm{nmol} / \mathrm{mol}$. It has a seasonal-diurnal cycle with a very strong summer maximum, which is observed at all times of the day (Fig. 6). The winter mixing ratios in $\mathrm{MC} 4$ are also relatively high, with values typical for semi-elevated and mountain locations (the lowest mixing ratios in $\mathrm{MC} 4$ equal those in $\mathrm{OC} 4$, which is representative of semi-elevated semi-polluted conditions). But unlike OC4, the diurnal and seasonal variations in this cluster are much stronger: the seasonal cycle amplitude ranges from $26 \mathrm{nmol} / \mathrm{mol}$ at $8 \mathrm{a} . \mathrm{m}$. to $45 \mathrm{nmol} / \mathrm{mol}$ at 11 a.m. in MC4 compared to $17 \mathrm{nmol} / \mathrm{mol}$ at 7 a.m. to $28 \mathrm{nmol} / \mathrm{mol}$ at $4 \mathrm{p} . \mathrm{m}$. in OC4; the diurnal cycle amplitude ranges from $8 \mathrm{nmol} / \mathrm{mol}$ in December to $22 \mathrm{nmol} / \mathrm{mol}$ in August in MC4 compared to $1 \mathrm{nmol} / \mathrm{mol}$ in December to $11 \mathrm{nmol} / \mathrm{mol}$ in August in OC4. This is an indication that MC4 shows an elevated location with very strong photochemical ozone production. One more feature of this cluster is the highest stratospheric contribution in comparison with other model clusters (Fig. 7). It is difficult to judge whether this is a real excess, or whether averaging within the clusters smoothes out similar elevated contributions for other particular locations. Also, it is interesting to see that the diurnal variations of the stratospheric contribution in MC4 are much stronger than in the other model clusters, but it is nearly constant in relative units and does not exceed $55 \%$.

The model cluster 5 (MC5) is represented by two gridboxes only. The average seasonal-diurnal variations in this cluster are presented in Fig. 5e. It is characterized by relatively high (the highest in winter in comparison with all the other model clusters) mixing ratios with a rather broad spring maximum (April). The range of the mixing ratios in MC4 is $32-52 \mathrm{nmol} / \mathrm{mol}$. This range is close to the range reported above for OC5 $(38-57 \mathrm{nmol} / \mathrm{mol})$, but the shape of the seasonal cycle is completely different. Unlike the other clusters, the seasonal minimum in OC5 is observed in July. The diurnal cycle in MC5 is rather weak, reaching its maximum in August $(3.7 \mathrm{nmol} / \mathrm{mol})$. It is likely that in this cluster the surface ozone is controlled by the processes with time-scales longer than a day. Since a slight increase in the mixing ratio occurs in the evening and the seasonality is characterized by the spring maximum only, this regime is characteristic of unpolluted locations with weak boundary layer photochemistry and dynamics. Elevated night and winter mixing ratios in comparison with background conditions can indicate either elevated locations (but then a secondary maximum should form in summer) or remote locations with reduced dry deposition. This is likely the case of observations over water surfaces. Figure 4 shows that the two locations representing MC5 are islands and hence, cluster MC5 represents the seasonal-diurnal cycle of the surface ozone over the ocean. It should be noted that the stratospheric relative contribution in MC5 never exceeds 45\% (Fig. 7b) and the diurnal variations are weak. This supposes that elevated mixing ratios in comparison with the other clusters are due to the lower deposition over the water surface instead of a stronger flux from the stratosphere or stronger photochemical production. 
The model cluster MC 6 (Fig. 5a) by its properties looks rather similar to OC6. This cluster is characterized by the lowest (in comparison with other model or observational clusters) ozone mixing ratios, in the range from 12 to $23 \mathrm{nmol} / \mathrm{mol}$. This range is comparable to that of OC6 (14$29 \mathrm{nmol} / \mathrm{mol}$ ). The seasonal maximum in MC6 is observed in March, coinciding in time with the maximum of the stratospheric contribution. In fact (Fig. 7a) the stratospheric contribution in absolute values does not change significantly between January and March and is at the level of $12 \mathrm{nmol} / \mathrm{mol}$. Similar to OC6, the diurnal cycle in MC6 is absent. Comparison of the seasonal-diurnal cycles for OC6 and MC6 (Fig. 8d and Fig. 9) shows that unlike the observations where the seasonal maximum is observed in winter (December-January), the seasonal maximum in MC6 is shifted to spring. The seasonal minimum in summer is reproduced in MC6, but 1 month later (in August) in comparison to OC6 (July). For the period from March to August the difference between the mixing ratios in MC6 and OC6 is less than $5 \mathrm{nmol} / \mathrm{mol}$. The largest differences between MC6 and OC6 are observed in autumn and winter, but still the model underestimates the observations by less than $8 \mathrm{nmol} / \mathrm{mol}$. The absolute stratospheric contribution in this cluster is the lowest $(12 \mathrm{nmol} / \mathrm{mol}$ at maximum), while the relative contribution is up to $55 \%$ (Fig. 7b). Analysing the geographical distribution of the grid-boxes contained in this cluster, we find southern hemispheric locations and the grid box containing Barrow. At the moment it is unclear why the model underestimates polar/remote mixing ratios and why a shift of the seasonality is observed in the model. One possibility is an underestimated flux from the stratosphere, however, we do not have the data to check this hypothesis (an analysis of the ozone sounding data is necessary). It is unlikely that background concentrations in the Southern Hemisphere are underestimated: a siteby-site comparison of model results and the observations (including Barrow) does not reveal any systematic differences. In total there are only 6 grid-boxes contained in $\mathrm{MC} 1$ covering 3 locations (of 4) representative for the similar regime in the measurements. Thus, it can be concluded that the variations of the surface ozone at remote locations, taking into consideration the limitations of the model setup and the uncertainty in the cluster centre detection, are captured reasonably well by the model.

\section{Conclusions}

In this study the main features of the surface ozone seasonaldiurnal variations are discussed. A statistical approach was applied to classify the main types of the seasonal-diurnal cycles based on the measurement data of 114 sites and the output from an atmospheric chemistry general circulation model. Some limitations in the analysis arose from the nonuniform spatial data coverage which makes the results more representative of the Northern Hemisphere. Nevertheless the obtained features represent the main global features of the surface ozone variations.

Our approach revealed 6 typical classes of the seasonaldiurnal cycles in the measurements. Background locations are characterized by a pronounced spring maximum which appears independent of the time of day. We conclude that it is probably not driven by local photochemical processes, but is rather of a dynamical origin. Four measurement clusters are characterized by a broad spring-summer maximum, where the summer part is more pronounced for daytime hours and plausibly due to photochemical production. A strong difference is seen between rural, semi-polluted non-elevated and semi-polluted semi-elevated sites with a more stable structure (less variability) and enhanced mixing ratios throughout the year for the latter. Polar/remote locations are also localized in one cluster and they are characterized by low absolute mixing ratios, a pronounced winter maximum and the absence of diurnal variations. It should be noted that both northern and southern hemispheric locations have such a regime of the surface ozone variations.

As for the measurements, the statistical approach has also been applied to model output. While making the comparison between the observed and the simulated seasonal-diurnal cycles, it should be kept in mind that the model data have different temporal and spatial resolution, and that identical monthly emissions have been prescribed each year. Nevertheless, the agreement between the model clusters and the observation clusters is rather good. We used the same number of clusters for the model output as for the measurements. The regime with low mixing ratios and without a diurnal cycle is reproduced by the model for 5 of 6 considered grid boxes of the Southern Hemisphere and for Barrow. 3 of 4 sites included in the corresponding cluster of observations are overlapping with this model cluster. The seasonal maximum in the model simulation is shifted to March and the minimum is shifted to August, which are respectively 2 and 1 months later than in the corresponding observational cluster. Background, rural and semi-polluted sites are merged for the model output in different clusters. For the cluster covering background locations the seasonal maximum is observed in April-May. For the model cluster covering rural locations and for the cluster covering semi-polluted locations the role of the photochemical production/destruction is likely to be overestimated, resulting in too low winter values and too high summer production. The amplitude of the diurnal cycle for the summer months in the more polluted cluster exceeds $40 \mathrm{nmol} / \mathrm{mol}$. At the same time the excess of the rural mixing ratios can be explained by a bias resulting from the applied de-trending procedure, which normalises to the beginning of the data period, which is different for the model compared to the observations. Furthermore, the inclusion of elevated locations in this cluster contributes to this bias. Taking into consideration the differences in the data sampling procedure (initial temporal resolution, the coarse spatial model resolution and the difference in the covered period), the obtained 
comparison demonstrates the ability of the model to reproduce the major regimes of the surface ozone variations quite well.

Acknowledgements. The work has been supported by the European Commission (Marie-Curie IIF project N 039905-FP6-2005Mobility-7) and the Russian Foundation for Basic Research (project 06-05-64427).

Edited by: M. Dameris

\section{References}

Ahammed, Y. N., Reddy, R. R., Gopal, K. R., Narasimhulu, K., Basha, D. B., Siva, L., Reddy, S., and Rao, T. V. R.: Seasonal variation of the surface ozone and its precursor gases during 2001-2003, measured at Anantapur (14.628 N), a semi-arid site in India, Atmos. Res., 80, 151-164, 2006.

Beaver, S. and Palazoglu, A.: A cluster aggregation scheme for ozone episode selection in the San Francisco, CA Bay Area, Atmos. Environ., 40(4), 713-725, 2006.

Cape, J. N., Methven, J., and Hudson, L. E.: The use of trajectory cluster analysis to interpret trace gas measurements at Mace Head, Ireland, Atmos. Environ., 34(22), 3651-3663, 2000.

Colette, A., Ancellet, G., and Borchi, F.: Impact of vertical transport processes on the tropospheric ozone layering above Europe. Part I: Study of air mass origin using multivariate analysis, clustering and trajectories, Atmos. Environ., 39(29), 5409-5422, 2005.

Crutzen, P. J.: A discussion of the chemistry of some minor constituents in the stratosphere and troposphere, Pure Appl. Geophys., 106, 1385-1399, 1973.

EMEP Assessment: Part I, European Perspective, eds. Lövblad, G., Tarrasón, L., Tørseth, K., and Dutchak, S., ISBN 82-7144-032-2, Oslo, October 2004.

Esser, P. J.: The effect of local and regional influences on ground level ozone concentrations under north European conditions, IMW-TNO Report R93/098, Delft, The Netherlands, 1993.

Everitt, B. S.: Cluster Analysis, third ed. Heinemann Education, London, 1993.

Fabian, P. and Pruchniewz, P. G.: Meridional distribution of ozone in the troposphere and its seasonal variations, J. Geophys. Res., 82, 2063-2073, 1977.

Felipe-Sotelo, M., Gustems, L., Hernàndez, I., Terrado, M., and Tauler, R.: Investigation of geographical and temporal distribution of tropospheric ozone in Catalonia (North-East Spain) during the period 2000-2004 using multivariate data analysis methods, Atmos. Environ., 40, 7421-7436, 2006.

Fiore, A., Jacob, D. J., Liu, H., Yantosca, R. M., Fairlie, T. D., and Li, Q.: Variability in surface ozone background over the United States: Implications for air quality policy, J. Geophys. Res., 108(D24), 4787, doi:10.1029/2003JD003855, 2003.

Gordon, A. D.: A Review of Hierarchical Classification, J. R. Stat. Soc. Ser. A-G., 150(2), 119-137, 1987.

Gros, V., Poisson, N., Martin, D., Kanakidou, M., Bonsang, B.: Observations and modeling of the seasonal variation of surface ozone at Amsterdam Island: 1994-1996, J. Geophys. Res., 103, 28 103-28 109, 1998.

Hill, T. and Lewicki, P.: STATISTICS: Methods and Applications, StatSoft, Tulsa, OK, 2006.
IPCC 2006: IPCC Guidelines for National Greenhouse Gas Inventories, Eggleston, H. S., Buendia, L., Miwa, K., Ngara, T. and Tanabe, K. (eds), IGES, Japan, 2006.

Hjellbrekke, A.-G. and Solberg, S.: Ozone measurements 2001, EMEP/CCC-Report, 4/2003, 2003.

Jöckel, P., Tost, H., Pozzer, A., Brühl, C., Buchholz, J., Ganzeveld, L., Hoor, P., Kerkweg, A., Lawrence, M. G., Sander, R., Steil, B., Stiller, G., Tanarhte, M., Taraborrelli, D., van Aardenne, J., and Lelieveld, J.: The atmospheric chemistry general circulation model ECHAM5/MESSy1: consistent simulation of ozone from the surface to the mesosphere, Atmos. Chem. Phys., 6, 50675104, 2006, http://www.atmos-chem-phys.net/6/5067/2006/.

Jonson, J. E., Simpson, D., Fagerli, H., and Solberg, S.: Can we explain the trends in European ozone levels?, Atmos. Chem. Phys., 6, 51-66, 2006, http://www.atmos-chem-phys.net/6/51/2006/.

Lelieveld, J. and Dentener, F. J.: What controls tropospheric ozone?, J. Geophys. Res., 105(D3), 3531-3551, 2000.

Lelieveld, J., van Aardenne, J., Fischer, H., de Reus, M., Williams, J., and Winkler, P.: Increasing Ozone over the Atlantic Ocean, Science, 304, p. 1483 , 2004.

Li, Q., Jacob, D. J., Fairlie, T. D., Liu, H., Martin, R. V., and Yantosca, R. M.: Stratospheric versus pollution influences on ozone at Bermuda: Reconciling past analyses, J. Geophys. Res., 107(D22), 4611, doi:10.1029/2002JD002138, 2002.

Linvill, D. E., Hooker, W. J., and Olson, B.: Ozone in Michigan's Environment 1876-1880, Mon. Weather Rev., 108, 1883-1891, 1980.

Monks, P. S.: A review of the observations and origins of the spring ozone maximum, Atmos. Environ., 34, 3545-3561, 2000.

Moody, J. L., Pszenny, A. P., Gaudry, A., Keene, W. C., Galloway, J. N., and Polian, G.: Precipitation composition and its variability in the southern Indian Ocean: Amsterdam Island, J. Geophys. Res., 96, 20 769-20 786, 1991.

Nolle, M., Ellul, R., Ventura, F., and Güsten, H.: A study of historical surface ozone measurements (1884-1900) on the island of Gozo in the central Mediterranean, Atmos. Environ., 39(30), 5608-5618, 2005.

Oltmans, S. J. and Levy II, H.: Seasonal cycle of surface ozone over the western North Atlantic, Nature, 358, 392-394, 1992.

Oltmans, S. J., Johnson, B. J., and Helmig, D.: Episodes of high surface ozone amounts at south pole during summer and their impact on the long-term surface ozone variation, Atmos. Environ., In Press, 2007.

Oltmans, S. J., Lefohn, A. S., Harris, J. M., Galbally, I. , Scheel, H. E., Bodeker, G., Brunke, E., Claude, H., Tarasick, D., Johnson, B. J., Simmonds, P., Shadwick, D., Anlauf, K., Hayden, K., Schmidlin, F., Fujimoto, T., Akagi, K., Meyer, C., Nichol, S., Davies, J., Redondas, A., Cuevas, E.: Long-term changes in tropospheric ozone, Atmos. Environ., 40, 3156-3173, 2006.

Omar, A. H., Won, J.-G., Winker, D. M., Yoon, S.-C., Dubovik, O., and McCormick, M. P.: Development of global aerosol models using cluster analysis of Aerosol Robotic Network (AERONET) measurements, J. Geophys. Res., 110, D10S14, doi:10.1029/2004JD004874, 2005.

Ordóñez, C., Mathis, H., Furger, M., Henne, S., Hüglin, C., Staehelin, J., and Prévôt, A. S. H.: Changes of daily surface ozone maxima in Switzerland in all seasons from 1992 to 2002 and dis- 
cussion of summer 2003, Atmos. Chem. Phys., 5, 1187-1203, 2005, http://www.atmos-chem-phys.net/5/1187/2005/.

Ordóñez, C., Brunner, D., Staehelin, J., Hadjinicolaou, P., Pyle, J. A., Jonas, M., Wernli, H., and Prevot, A. S. H.: Strong influence of lowermost stratospheric ozone on lower tropospheric background ozone changes over Europe, Geophys. Res. Lett., 34(7), L07805, doi:10.1029/2006GL029113, 2007.

Scheel, H. E., Areskoug, H., Geiß, H., Gomiscek, B., Granby, K., Haszpra, L., Klasinc, L., Kley, D., Laurila, T., Lindskog, A., Roemer, M., Schmitt, R., Simmonds, P., Solberg, S., and Toupance, G.: On the Spatial Distribution and Seasonal Variation of Lower-Troposphere Ozone over Europe, J. Atmos. Chem., 28, 11-28, 1997.

Scheel, H. E., Brunke, E.-G., and Seiler, W.: Trace Gas Measurements at the Monitoring Station Cape Point, South Africa, between 1978 and 1988, J. Atmos. Chem., 11, 197-210, 1990.

Scheel, H. E.: Ozone Climatology Studies for the Zugspitze and Neighbouring Sites in the German Alps, TOR-2 Final Report, 134-139, 2003.

Schuepbach, E., Friedli, T. K., Zanis, P., Monks, P. S., and Penkett, S. A.: State space analysis of changing seasonal ozone cycles (1988-1997) at Jungfraujoch (3580 $\mathrm{m}$ above sea level) in Switzerland, J. Geophys. Res., 106(D17), doi:20.413/2000JD900591, 2001.

Stevenson, D. S., Dentener, F. J., Schultz, M. G., Ellingsen, K., van Noije, T. P. C., et al.: Multimodel ensemble simulations of present-day and near-future tropospheric ozone, J. Geophys. Res., 111, D08301, doi:10.1029/2005JD006338, 2006.
Tarasova, O. A., Elansky, N. F., Kuznetsov, G. I., Kuznetsova, I. N., and Senik, I. A.: Impact of air transport on seasonal variations and trends of surface ozone at Kislovodsk High Mountain stations, J. Atmos. Chem., 45, 245-259, 2003.

Tropospheric Ozone Research (TOR-2): in: Towards Cleaner Air for Europe - Science, Tools and Applications, Part 2. Overviews from the Final Reports of the EUROTRAC-2 Subprojects, edited by: Midgley, P. M., and Reuther, M., Margraf Verlag, Weikersheim, 2003.

Tryon, R. C.: Cluster Analysis, Ann Arbor, MI: Edwards Brothers, 1939.

Varotsos, C., Kondratyev, K. Ya., and Efstathiou, M.: On the seasonal variation of the surface ozone in Athens, Greece, Atmos. Environ., 35(2), 315-320, 2001.

Sunwoo, Y. and Carmichael, G. R.: Characteristics of background surface ozone in Japan, Atmos. Environ., 28(1), 25-37, 1994.

Vingarzan, R.: A review of surface ozone background levels and trends, Atmos. Environ., 38, 3431-3442, 2004.

Zvyagintsev, A. M.: Main periodicities of the temporal variability of the surface ozone in Europe, Meteorology and Hydrology, 10, 46-55, 2004. 